\title{
SCHEDULING OF ELECTRICAL VEHICLE CHARGING FOR A CHARGING FACILITY WITH SINGLE CHARGER OR MULTIPLE CHARGERS
}

by

\author{
Isuru Pasan Dasanayake Vidanalage \\ Bachelor of Science in Engineering, \\ University of Moratuwa, Moratuwa, Sri Lanka, 2014
}

\begin{abstract}
A thesis
presented to Ryerson University

in partial fulfillment for the degree of

Master of Applied Science

in the program of

Electrical and Computer Engineering
\end{abstract}

Toronto, Ontario, Canada, 2018

(C) Isuru Pasan Dasanayake Vidanalage, 2018 


\begin{abstract}
AUTHOR'S DECLARATION
I hereby declare that I am the sole author of this thesis. This is a true copy of the thesis, including any required final revisions, as accepted by my examiners.

I authorize Ryerson University to lend this thesis to other institutions or individuals for the purpose of scholarly research.

I further authorize Ryerson University to reproduce this thesis by photocopying or by other means, in total or in part, at the request of other institutions or individuals for the purpose of scholarly research.

I understand that my thesis may be made electronically available to the public.
\end{abstract}




\begin{abstract}
Thesis Title: Scheduling of Electrical Vehicle Charging for a Charging Facility with Single Charger or Multiple Chargers

Degree: Master of Applied Science
\end{abstract}

Convocation year: 2018

Student Name: Isuru Pasan Dasanayake Vidanalage

Graduate program: Electrical and Computer Engineering

University: Ryerson University

Merchant-owned charging stations will replace gasoline stations in the near future. As charging times of electric vehicles (EV) may be significant, without optimization, customers will wait to get charged without knowing the actual period of charging. In this thesis, two optimal scheduling methods for charging electric vehicles were developed for merchant-owned charging facilities, the first with a single charger and the second with multiple chargers.

In the mathematical model for the single merchant-owned charging station, the problem is formulated as a hybrid nonlinear optimization model and solved using a backward recursive algorithm with nonlinear optimization solvers. As for a single charger, a hybrid system framework was used to capture the tradeoff between demand charges and speed of charging. 
For the merchant-owned multiple chargers case, the problem is formulated as a mixed integer linear optimization challenge with three-dimensional matrices characterizing the solution space and was solved using the MOSEK optimization toolbox in MATLAB.

The proposed algorithms have been analyzed for different penalty factors which were imposed on total waiting time of each EV. Final results are analyzed and discussed. 


\section{ACKNOWLEDGEMENTS}

I would like to express my deepest appreciation to Dr. Bala Venkatesh for giving me the opportunity to pursue my graduate studies at the department of Electrical and Computer Engineering at Ryerson University. Furthermore, I am really thankful to Dr. Bala Venkatesh for giving me the opportunity and directing me to gather knowledge and expand my horizons through valuable conferences and seminars throughout the period of study. Without his guidance, encouragement and persistent help this dissertation would not have been possible. It was a great privilege and an honor to study under his supervision.

Financial assistance provided by the Centre for Urban Energy and Department of Electrical and Computer Engineering is gratefully acknowledged.

I would like to thank Dr. Walmir Freitas and Mr. Ricardo Torquato for the immense help towards writing and reviewing my research papers.

I specially acknowledge the guidance, knowledge and support given by Dr. Chandrabhanu Opathella throughout the period of study. I would like to extend my gratitude to Dr. Amirnaser Yazdani, Dr. Kaamran Raahemifar, Dr. David Xu and Dr. Raymond Phan for their valuable teachings. With their help, I was able to improve my knowledge in electrical engineering greatly.

I would also like to thank my colleagues and friends at the Centre for Urban Energy at Ryerson University. A special word of thanks also goes to my family for their continuous support and encouragement. 


\section{TABLE OF CONTENTS}

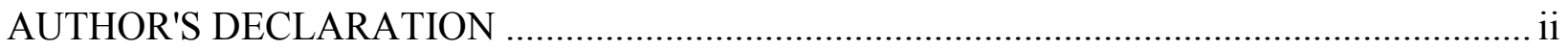

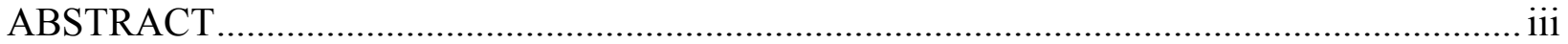

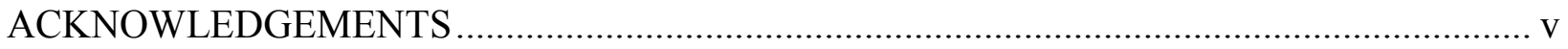

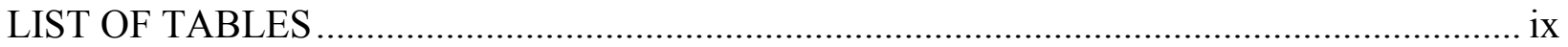

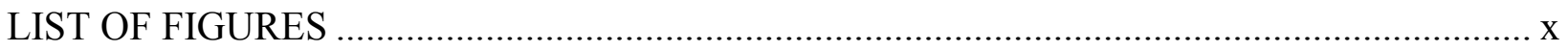

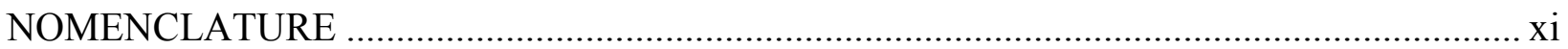

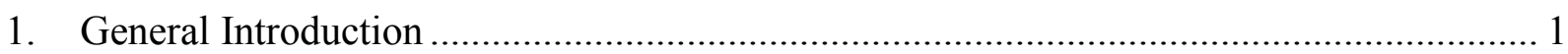

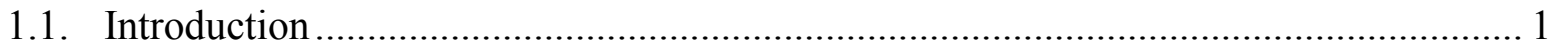

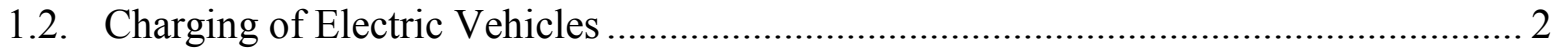

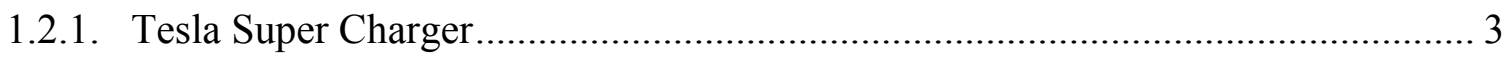

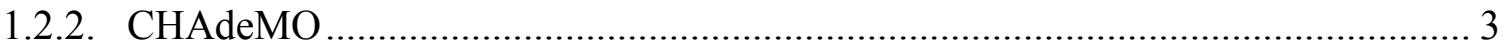

1.2.3. Combined Charging System (CCS) …………................................................ 4

1.3. Day-Ahead EV Charging Schedule ………….......................................................... 5

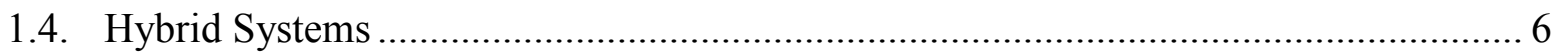

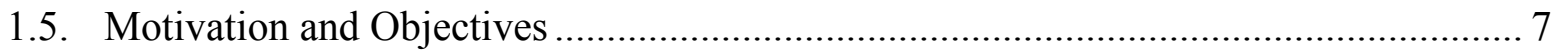

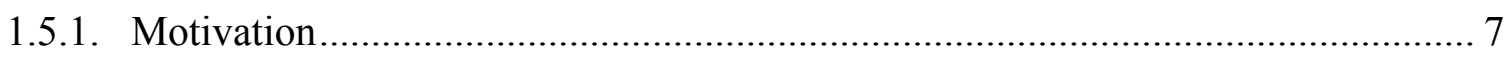

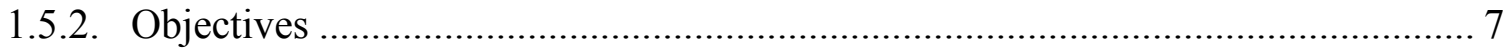

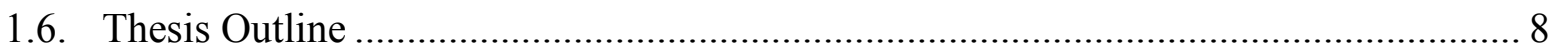

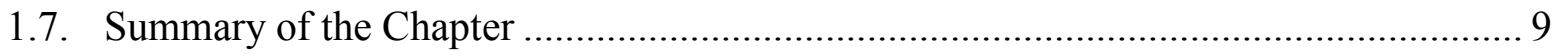

2. Literature Survey ............................................................................................... 10

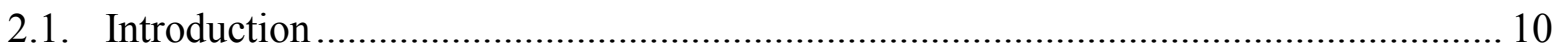

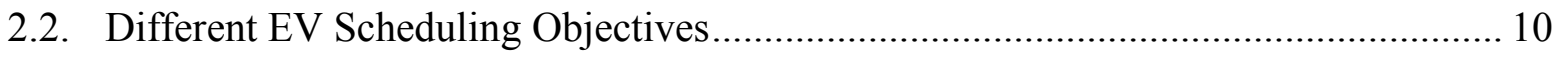

2.3. Optimal Control of Discrete-Continuous Hybrid Systems ......................................... 13

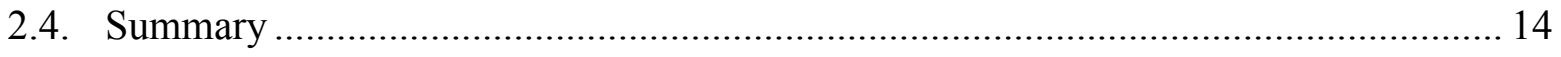

3. Electrical Vehicle Charging for a Charging Facility with a Single Charger ..................... 15

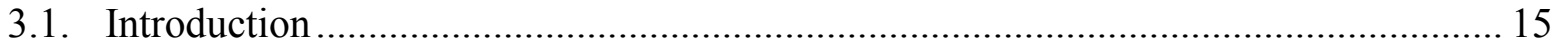




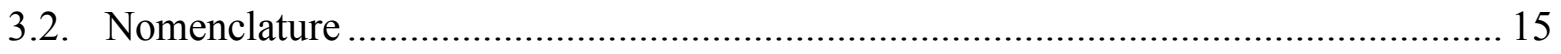

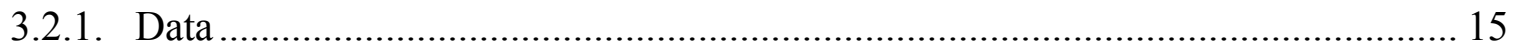

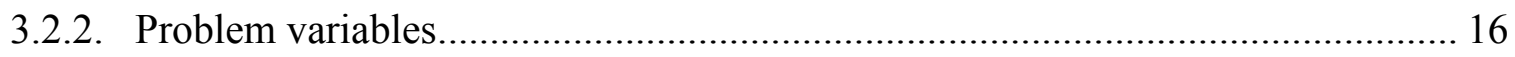

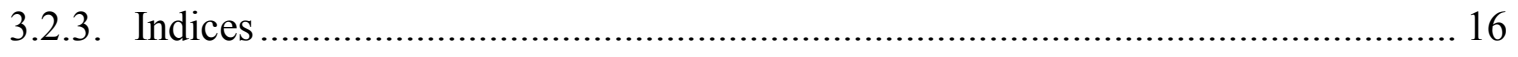

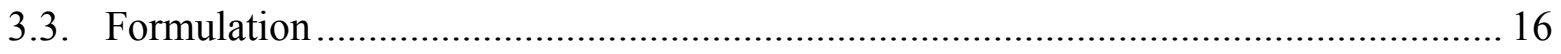

3.3.1. Type of Costs Associated with the Objective Function....................................... 16

3.3.2 Constraints Considered for the Objective Function............................................. 17

3.3.3 Objective Function......................................................................................... 18

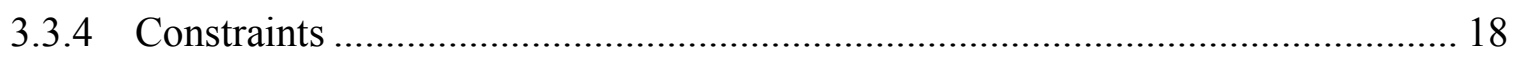

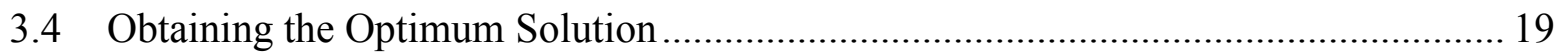

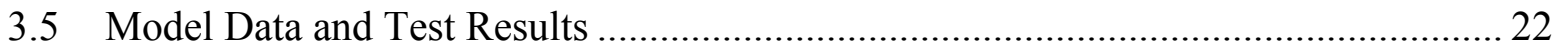

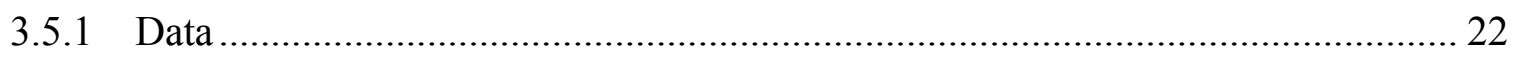

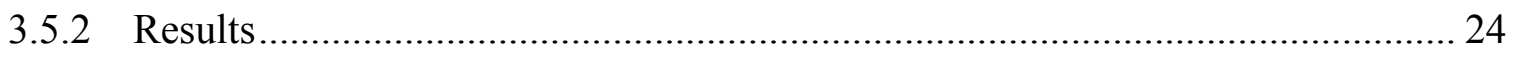

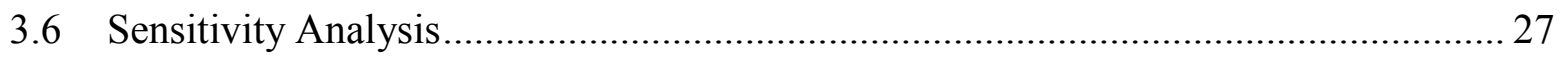

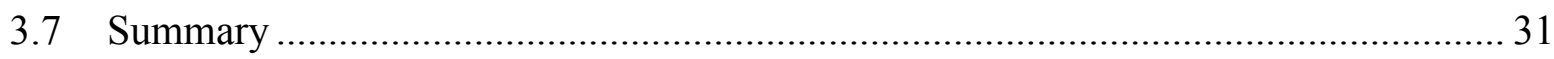

4 Electrical Vehicle Charging for a Charging Facility with Multiple Chargers ................... 33

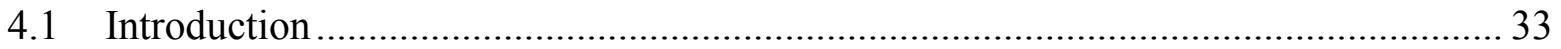

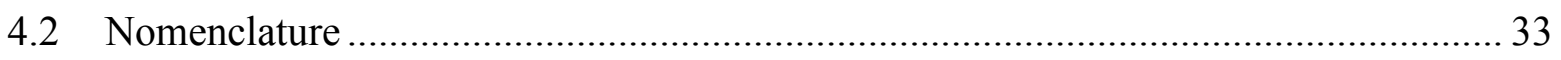

Data 33

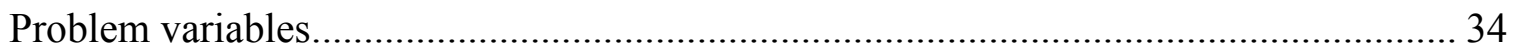

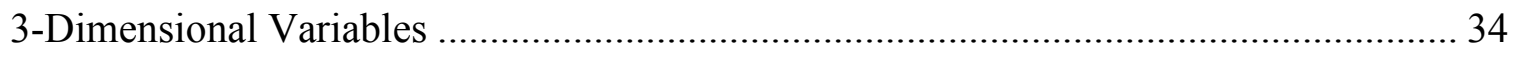

Indices 34

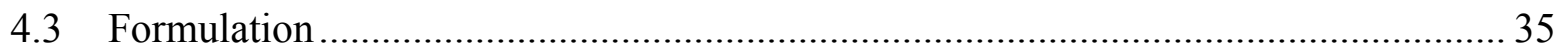

4.3.1 Type of Costs Associated with the Objective Function ........................................ 35

4.3.2 Constraints Considered for the Objective Function............................................. 36

4.3.3 Objective Function ...................................................................................... 36

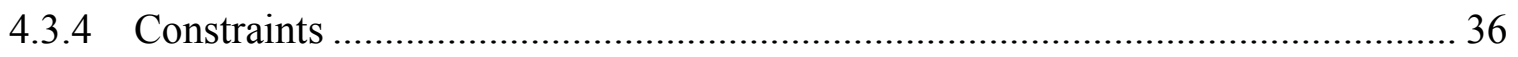

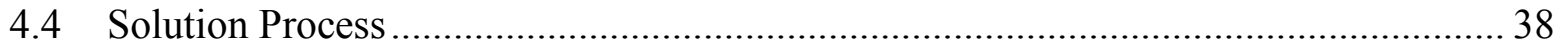

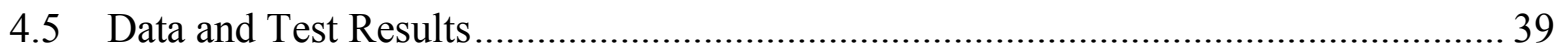

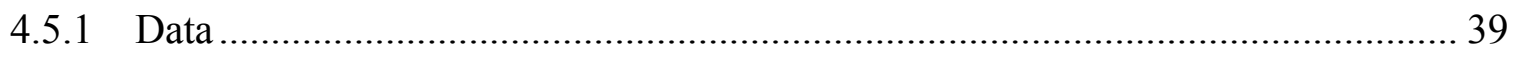

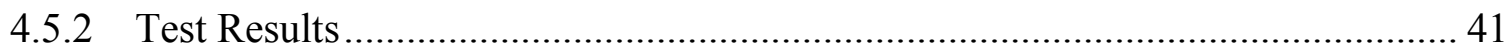




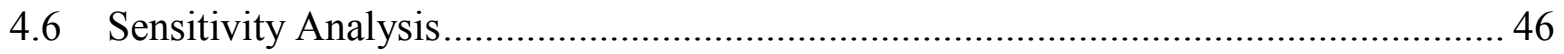

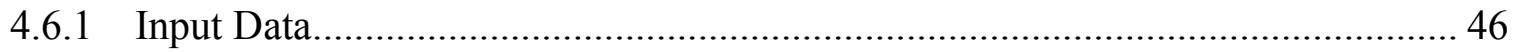

4.6.2 Effect on the Total Charging Cost ................................................................... 48

4.6.3 Effect on the Total Cost Variation Throughout the Day....................................... 50

4.6.4 Effect on the Total Charging Cost per EV ……………….................................. 51

4.6.5 Comparison with Related Work in the Literature.............................................. 53

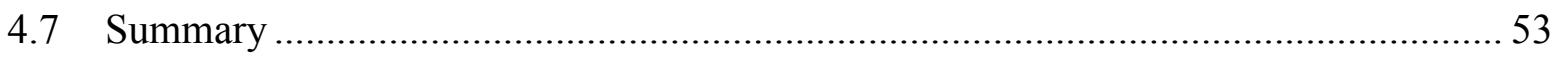

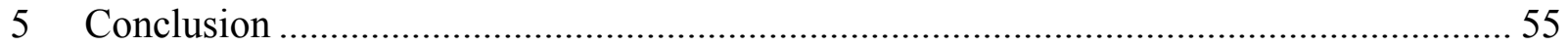

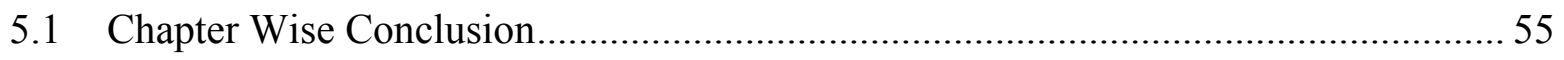

5.1.1 Chapter 1: General Introduction .................................................................... 55

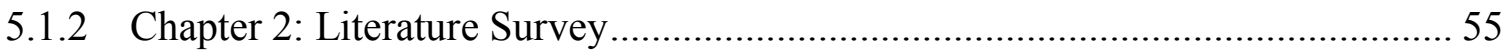

5.1.3 Chapter 3: Electrical Vehicle Charging for a Charging Facility with a Single

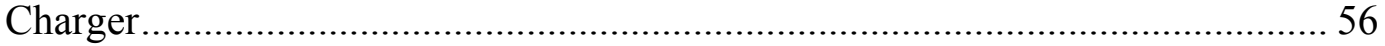

5.1.4 Chapter 4: Electrical Vehicle Charging for a Charging Facility with Multiple

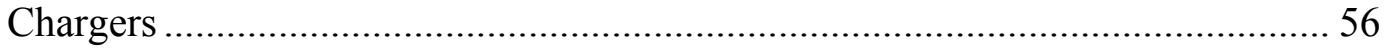

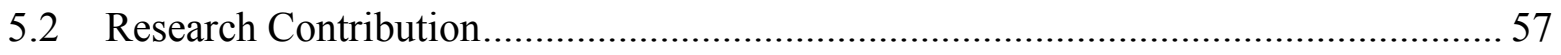

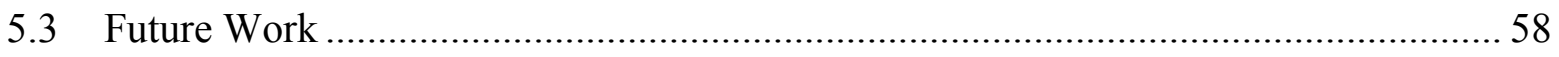

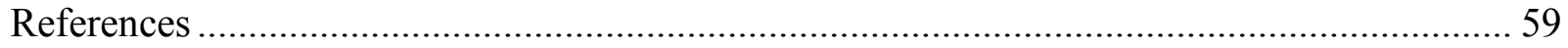




\section{LIST OF TABLES}

Table 1.1 Different Charging Levels for EV Charging ............................................................ 3

Table 3.1 Efficiency of CHAdeMO Charger........................................................................... 23

Table 3.2 Arrivals of EV to the Charging Facility............................................................ 23

Table 3.3 Arrivals of EVs to the Charging Facility (For the Sensitivity Analysis) ................... 27

Table 3.4 Summary of the Sensitivity Analysis............................................................... 28

Table 3.5 Total Waiting Time for Each Value of the Penalty for Waiting (KW).................... 30

Table 4.1 Arrivals of EVs to the Charging Facility ............................................................. 41

Table 4.2 Matrix U for charger \#1 and charger \#2 .................................................................. 43

Table 4.3 Matrix S for charger \#1 and charger \#2 ............................................................... 44

Table 4.4 Matrix P for charger \#1 and charger \#2 …............................................................ 45

Table 4.5 Cost Breakdown for the Analysis of Sample Data Set .......................................... 45

Table 4.6 Arrivals of EVs to the Charging Facility ............................................................... 46

Table 4.7 Cost Breakdown of Each Case............................................................................... 48

Table 4.8 Total Waiting Time for Each Value of the Penalty for Waiting $(K W) \ldots \ldots \ldots \ldots \ldots \ldots \ldots . . . . . . . . . .49$ 


\section{LIST OF FIGURES}

Figure 1.1 Global EV Sales Based on the Charging Standards [20] ...................................... 4

Figure 1.2 Global Cumulative Charging Station Deployment (2014-2020) [20]....................... 5

Figure 3.1 Flow chart of the backward recursive algorithm ............................................... 21

Figure 3.2 Time Line for $24 \mathrm{~h}$ (without backward recursive algorithm) ................................. 24

Figure 3.3 Time Line for $24 \mathrm{~h}$ (with backward recursive algorithm) ...................................... 25

Figure 3.4 Time Line for $24 \mathrm{~h}$ (with and without backward recursive algorithm) .................... 26

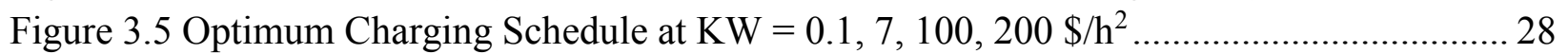

Figure 3.6 Demand Charge and Total Penalty Cost Variation for Different Values of

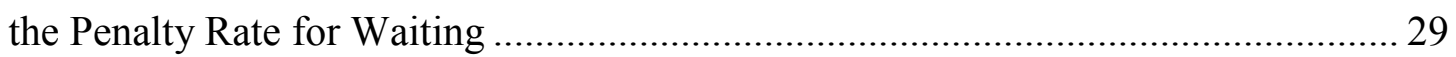

Figure 3.7 Demand Charge Variation for Different Penalty Rates......................................... 30

Figure 4.1 View of 3-Dimentional Matrices.............................................................................. 38

Figure 4.2 Time Line for $24 \mathrm{~h}$ for Charger \#1 and \#2 ......................................................... 42

Figure 4.3 Time Line for 24h for Charger \#1, KW=0.1, 7, 100 and $200 \$ / \mathrm{h}$. ........................ 47

Figure 4.4 Time Line for 24h for Charger \#2, KW=0.1, 7, 100 and $200 \$ / \mathrm{h}$.......................... 47

Figure 4.5 Cost Variation against Rate of Penalty Cost ....................................................... 49

Figure 4.6 Demand Charge Variation for Different Penalty Rates.......................................... 50

Figure 4.7 Total Cost for the Charging Facility for Different Penalty Cost Rates ..................... 51

Figure 4.8 Cost for Each EV for Different Rates of Penalty Costs ........................................ 52 


\section{NOMENCLATURE}

\section{Data}

$a_{k}=$ Arrival time of the $\mathrm{k}^{\text {th }}$ vehicle (hours)

$N=$ Number of vehicles coming to the charging station during the day

$E_{k}=$ Energy requirement of the $\mathrm{k}^{\mathrm{th}}$ vehicle $(k W h)$

$K E=$ Electrcity rates $(\$ / \mathrm{kWh})$

$K P=$ Demand charge $(\$ / \mathrm{kW})$

$K W=$ Rate of penalty charge for waiting $\left(\$ /\right.$ hour $\left.^{2}\right)$

$b, c$ and $d=$ Constants of the loss factor

$P_{\max }=$ Maximum charging capacity of the charging station $(\mathrm{kW})$

$N C=$ Number of charging stations

$N E=$ Number of Electrical Vehicles

$N T=$ Number of total time segments

Energy $_{e}=$ Energy requirement of Electric vehicle ' $\mathrm{e}^{\prime}(\mathrm{kWh})$

$\Delta t=$ Duration of an individual time segment in hours(hour)

$K E_{t}=$ Electricity rates $(\$ / \mathrm{kWh})$

$K P=$ Demand charge $(\$ / \mathrm{kW})$

$K W=$ Rate of penatly charge for waiting (\$/hour)

$N=$ Number of vehicles coming to the charging station during the day

$a_{e}=$ Arrival time of the $\mathrm{e}^{\text {th }}$ vehicle (hours)

$P_{\text {max }}=$ Maximum charging capacity of each charging station $(\mathrm{kW})$

$P M_{\text {max }}=$ Maximum power capacity of the transformer connected to all chargers (kW) 


\section{Problem variables}

$P M=$ Recorded Maximum power, during the day $(\mathrm{kW})$

$x_{k}=$ Charging completion time of the $\mathrm{k}^{\text {th }}$ vehicle (hours)

$P_{k}=$ Charging power of $\mathrm{k}^{\text {th }}$ vehicle $(\mathrm{kW})$

$E_{e}=$ Energy cost of Electric vehicle ' $\mathrm{e}^{\prime}(\$)$

$T_{e}=$ Total waiting time of each $\mathrm{EV}^{\prime} \mathrm{e}^{\prime}$ (hour)

$P M=$ Recorded maximum power, during the day $(\mathrm{kW})$

\section{Dependent variables}

$\mathrm{U}_{\text {tec }}=$ Status of electric vehicle ' $\mathrm{e}$ ' getting charged at charger ' $c$ ', at time slot ' $\mathrm{t}$ '

$S_{\text {tec }}=$ Status when an EV ' $e$ ' starts charging, at charger ' $c$ ', at time slot ' $t$ '

$P_{\text {tec }}=$ Charging power of electric vehicle 'e' getting charged at charging station ' $c$ ', at time

\section{Indices}

$\mathrm{k}=$ electric vehicle number

$\mathrm{e}=$ Electric vehicle number

$\mathrm{t}=$ Time segment number

$\mathrm{c}=$ Charger number 


\section{Chapter 1}

\section{General Introduction}

\subsection{Introduction}

Increasing greenhouse gas emissions (GHG) have become a growing concern. The transport sector is responsible for about $23 \%$ of global greenhouse gas emissions (GHG). The transport sector in Canada accounts for about $24 \%$ of the country's total GHG emissions [1],[2]. Considering this huge impact of the transport sector on total GHG emissions, Electric Vehicles (EV) will play an important role in transitioning to a GHG free environment. Adoption of EVs in society is growing and prices of EVs are dropping to equal or better than those of gasoline driven vehicles.

Currently, EVs account for a small fraction of global vehicle stock, making their impact on global fuel consumption insignificant. Nevertheless, in many countries such as Norway, the Netherlands and China there has been a huge growth of EV sales since 2011 [1]. Today the most dominant fuels in the transport sector are gasoline, diesel and compressed natural gas. It has been predicted that the percentage of the transport sector using petroleum as fuel will dropped from $96 \%$ in 2012 to $88 \%$ in 2040 [3]. Meanwhile, the share of the transport sector using electricity as its source of energy will have positive growth [3]. When it comes to the reduction of carbon emissions in the transport sector, governments have a major role to play. Eight major nations ( Canada, China, France, Japan, Norway, Sweden, the United Kingdom and the United States) have signed a Government Fleet Declaration, pledging to increase the share of EVs in their

individual government owned fleets [4]. They have invited other countries to join them. Some governments have introduced incentive programs to support more EVs in their respective countries or provinces. The Government of Ontario in Canada is offering up to $\$ 1,000$ to help people to purchase and install EV chargers for home or business use [5]. With these incentive 
programs, the advancement of technology, the reduction in battery costs and the increasing levels of energy density in batteries, EVs could become less expensive than gasoline driven vehicles and more popular in society.

Some major EV initiative projects have been introduced by many countries including the US [6] [7], the UK [8], Germany [9] and Canada [5]. Due to the growth in EVs, many countries have started to install level 2 and level 3 chargers along their highways. Examples of other government initiatives include the EV Chargers Ontario (EVCO) grant program, which is working with 24 public and private sector partners to install $500 \mathrm{EV}$ charging stations across the province [10]. As of 2015, there were over 5,836 charging stations available in Germany and plans to establish 1,400 more DC fast charging station across the country by 2017 [9].

\subsection{Charging of Electric Vehicles}

The supply voltage for EV chargers dictates their power rating and that decides the time for charging of EVs. The Society of Automotive Engineers has published a data sheet comparing charging time with different charging levels for a battery powered EV with a battery of $25 \mathrm{kWh}$ [11], with the times outlined in Table 1.1.

An EV can be either charged at home at residential voltage levels or at a commercial charging facility at a higher voltage level. With the lower supply voltage and the limited charging power in residential chargers, it takes a longer time to charge the EVs. However, at commercial EV charging facilities, at higher voltage levels and higher power ratings, EVs can be charged faster in a shorter time. 
Table 1.1 Different Charging Levels for EV Charging

\begin{tabular}{|l|c|c|}
\hline \multicolumn{1}{|c|}{ Charging Level } & Charging status & Time \\
\hline AC Level 1 (120V), 12-16A & SOC from $20 \%$ to $100 \%$ & $17 \mathrm{~h}$ \\
\hline AC Level 2 (240V), 80A & SOC from $20 \%$ to $100 \%$ & $7 \mathrm{~h}$ \\
\hline DC Level 1 (200-450V), 80A & SOC from $20 \%$ to $100 \%$ & $1.2 \mathrm{~h}$ \\
\hline DC Level 2 (200-450V), 200A & SOC from $20 \%$ to $80 \%$ & $20 \mathrm{~min}$ \\
\hline DC Level 3 (200-600V), 400A & SOC from $20 \%$ to $80 \%$ & $<10 \mathrm{~min}$ \\
\hline
\end{tabular}

The first two options given in Table 1.1 can be installed in households. It can be observed that

DC Level 1, 2 and 3 chargers are much faster. Generally, DC charging options are available only at a commercial level charging facility. With the growing EV industry and people's busy schedules, fast charging will become a necessity.

As of now, there are many EV fast charging standards available. Only certain sets of EVs are compatible with each standard. In case their vehicles are not compatible, some manufacturers have introduced adapters. A few EV fast charging standards are as follows.

\subsubsection{Tesla Super Charger}

This super charger was introduced by Tesla. This is one of the popular DC charging methods available, with a charging power up to120kW [12], [13]. Generally, all the Tesla EVs can be charged using Tesla super chargers.

\subsubsection{CHAdeMO}

Toyota, Nissan, Mitsubishi and Fuji Heavy industries partnered to establish the CHAdeMO quick charge standard in March 2010. It has been the most popular charging standard in the world. It has the capability to charge up to $50 \mathrm{~kW}$ and it is planned to develop it up to $150 \mathrm{~kW}$ in the near future [14]. The most popular EV manufacturers to use the CHAdeMO standard for EV 
charging are Nissan, Mitsubishi, Kia, Peugeot, Toyota and Honda [15]. Since this standard only works with a certain set of EVs, Tesla has introduced an adapter to charge Tesla EVs with CHAdeMO charging standards [16].

\subsubsection{Combined Charging System (CCS)}

This method of charging combines single phase with rapid three-phase charging at the maximum of $43 \mathrm{~kW}$, as well as DC current at a maximum of $200 \mathrm{~kW}$. It is planned to extend the charging power up to $300 \mathrm{~kW}$ in the future [17]. The most popular EVs charging with this method, are the Volkswagen e-golf [18] and the BMW i3 [19].

The global status of EV sales based on the charging standard and the trend of global charging station deployment up to 2020 are shown in Figure 1.1 and Figure 1.2 respectively.

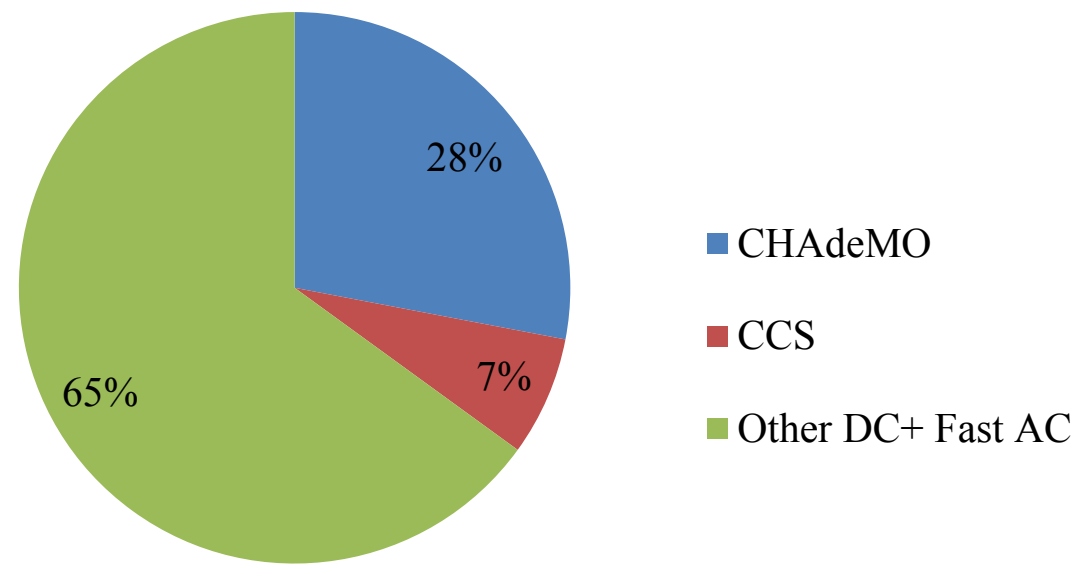

Figure 1.1 Global EV Sales Based on the Charging Standards [20] 


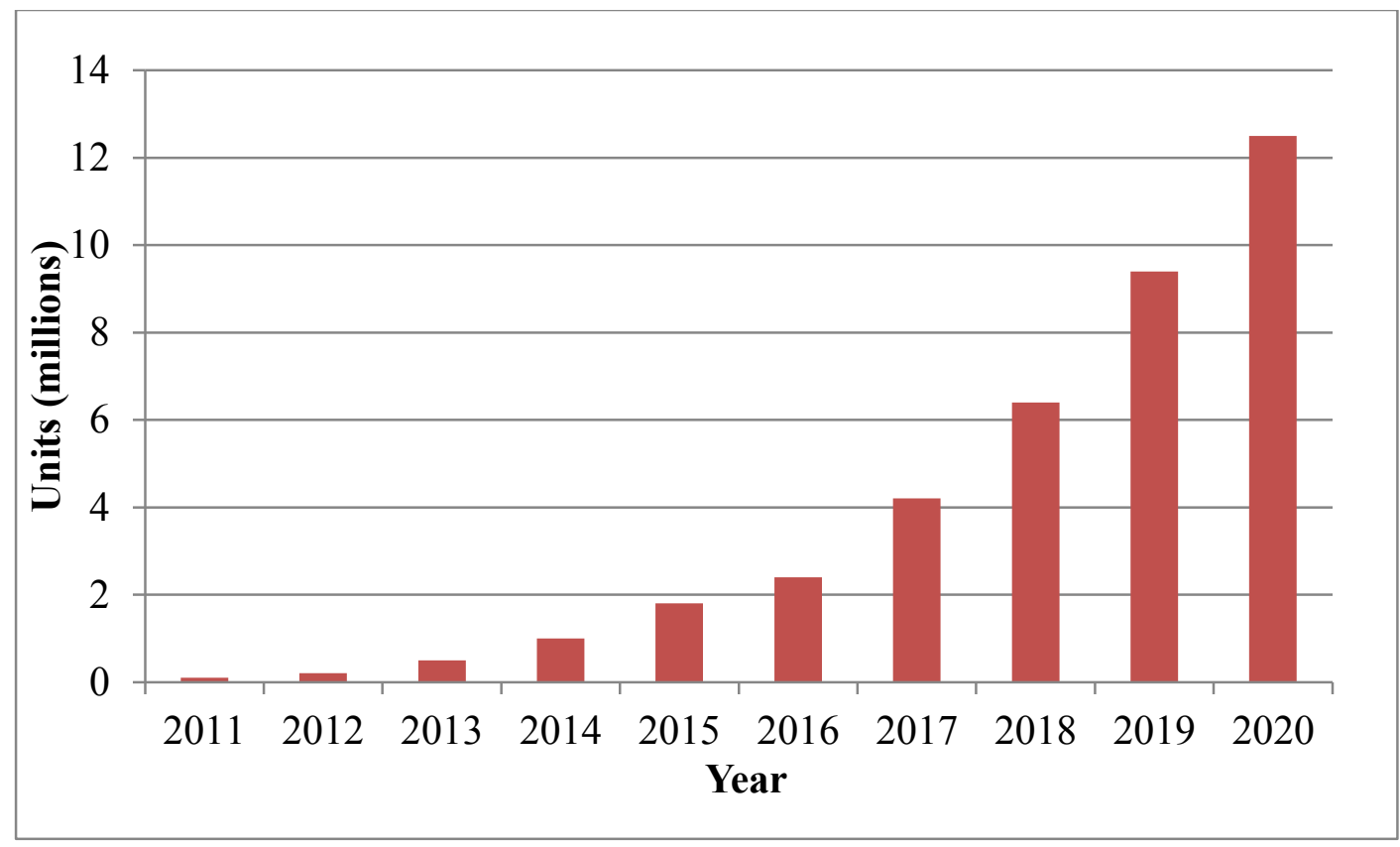

Figure 1.2 Global Cumulative Charging Station Deployment (2014-2020) [20]

\subsection{Day-Ahead EV Charging Schedule}

EVs need to be charged frequently and they can be charged at home or at a merchant-owned charging facility. Fast charging chargers have the ability to charge the EV in a shorter period of time, using higher power.

Even in the case of fast public charging stations, charging an EV with electrical energy takes more time compared to fueling up a gas-powered vehicle. Depending on the requirement, there can be many customers lining up at a charging station to charge their EVs.

Therefore, this research is mainly focused on developing a charging schedule for a charging facility with a minimum cost. A schedule is developed, based on the list of EVs which are planning to come to the charging facility during the next day.

The cost of charging EVs at a charging facility depends on many factors such as power capacity of the transformer, power capacity of chargers, maximum demand charge, electricity rates, etc. If 
an EV must be in a queue for a long time to start charging and/or takes more time to charge at a lower power level, that can also be reflected in the cost. Apart from the queuing time, cost can be varied based on the efficiency of the charger and the level of maximum charging capacity. Unlike charging at home, where the cost mainly depends on the energy requirement, at a charging facility cost can vary over a wide range, due to the many factors explained earlier.

From the customer point of view, if there are multiple charging facilities available in the neighborhood, they have the option to go to the cheapest charging facility where they could experience a longer waiting time or choose a more expensive option, where they have a shorter waiting time.

A charging facility can calculate the cost associated with the next customers' requirement, based on the current status of the facility. In that way, a customer can know about charging costs instantly. As such, a customer can make an informed decision after getting prices from all charging facilities in the neighborhood. The mathematical optimization model proposed in this research helps to calculate the minimum cost of charging EVs while maximizing profits for the merchant-owned charging facility.

\subsection{Hybrid Systems}

A dynamic system which consists of both continuous and discrete dynamic behavior is defined as a hybrid system [21]. A function to model charging costs of an EV is considered as a continuous function, which is continuous throughout the charging time. There can be a time gap between charging of two consecutive EVs, based on the finishing time of charging the first EV and the arrival time of the next EV. The complete function modeling charging of multiple EVs at a single charging facility, separated by time intervals, causes the total model to be a 
discontinuous set of continuous functions, also known as a hybrid system. So, the charging process of EVs at a charging facility can be defined as a hybrid system.

\subsection{Motivation and Objectives}

\subsubsection{Motivation}

With the growing number of EVs on the road, there will be an increasing demand for charging facilities. Since it takes a considerable amount of time to charge an EV, if a charging facility is not properly organized, EV owners will have to wait to get their EVs charged without knowing the time required to complete charging. In addition, charging facility owners will not be aware of optimum charging power levels and the charging times such that their costs are minimized.

Much recent research to calculate the optimum charging schedule has been developed from the EV owner's perspective or focused on grid impact. However, in a merchant-owned EV charging facility, the charging facility owner will want to maximize profits or minimize costs. Hence, the main challenge is to find the optimum charging schedule that minimizes the cost of charging from the EV charging facility owner's perspective.

\subsubsection{Objectives}

The main objectives of this thesis are as below:

- Develop a mathematical formulation and an algorithm to determine the optimum EV charging schedule to charge a set of EVs over a 24-hour period such that the cost of charging is minimized considering a merchant-owned charging facility with a single charger.

- Develop a mathematical formulation and an algorithm to determine the optimum EV charging schedule to charge a set of EVs over a 24-hour period such that the cost of charging is minimized considering a merchant-owned charging facility with multiple chargers. 


\subsection{Thesis Outline}

This thesis contains five chapters, which are briefly explained below:

\section{General Introduction}

The main purpose of this chapter is to introduce EV charging information and present the scope of this thesis. Available EV charging methods and their importance are briefly described.

\section{Literature Survey}

This chapter presents some of the existing research about optimization of EV charging. In addition, research studies on cost optimization of hybrid systems are presented. An algorithm used to optimize a hybrid system is used for cost minimization of an EV charging facility with a single charger.

3. Electrical Vehicle Charging for a Charging Facility with a Single Charger

A formulation and algorithm, results from a study on an example data set, and results of a sensitivity analysis for charging a set of electric vehicles over a 24-hour period in a merchantowned charging facility with a single charger are presented in this chapter.

4. Electrical Vehicle Charging for a Charging facility with Multiple Chargers

A formulation and algorithm, results from a study on an example data set, and results of a sensitivity analysis for charging a set of electric vehicles over a 24-hour period in a merchantowned charging facility with multiple chargers are presented in this chapter.

\section{Conclusion}

In this chapter, a summary of key findings and observations along with suggestions for future work for this research topic are presented. 


\subsection{Summary of the Chapter}

This chapter introduced electric vehicle charging and its importance. Along with electric vehicle growth, the need for electric vehicle charging facilities is also growing. Existing methods of electric vehicle charging were briefly discussed. The nature of optimizing the schedule of electric vehicle charging was explained. The motivation and objectives of the thesis and a thesis outline that gives an insight into all the chapters of this thesis were presented. 


\section{Chapter 2}

\section{Literature Survey}

\subsection{Introduction}

There are many research studies to address the issue of finding an optimal schedule for EV charging at a charging facility. In this chapter, the research studies are reviewed and presented with respect to optimal control of discrete-continuous hybrid systems and different EV scheduling objectives.

\subsection{Different EV Scheduling Objectives}

EVs can be charged and discharged to achieve different objectives. EV charging schedules with Vehicle-to-Grid (V2G) and Grid-to-Vehicle (G2V) control strategies have been discussed in Ref. [22],[23], [24], [25],[26],[27], [28], [29] and [30].

In [22]-[23], methodologies to develop charging schedules to regulate grid frequency through V2G control of EVs are presented. The optimization objective of these scheduling problems is grid frequency regulation. With the developed schedules, grid frequency fluctuations can be suppressed by frequency droop control while satisfying the charging requirement. There are EV scheduling algorithms built for the objective of grid intermittency minimization in [24], [25], [26] and [27]. When there is a high penetration of renewable energy (RE) to the grid, V2G and G2V control can be used to develop an EV charging schedule to deal with the supply intermittency [24]. EV can be used as energy storage to address this issue. When there is an intermittent renewable energy supply, it can be stored in EVs and discharged to the grid during peak hours to reduce energy from expensive power plants. Research paper [27] specifically discusses about collaboration between wind power plant owners and EV owners to increase their revenue and incentives through a V2G approach. Optimal EV charging schedules are used to 
mitigate distribution grid voltage problems caused by solar generation [25] and to supply ancillary services to the grid [28]. Similar to the previous research, EV can be used as energy storage to store energy and use it to reduce voltage problems. In Research [29], authors propose an approach to make microgrid more reliable, stable and cost effective through a methodology of jointly controlling EV charging and electricity consumption of home appliances. In [30], authors suggest an optimal scheduling methodology to minimize the cost of EV charging to the grid. This research study propose a globally optimal scheduling scheme and a locally optimal scheduling scheme for EV charging and discharging. The cost was minimized from the grid point of view.

These V2G and G2V control strategies are mainly used to control the grid parameters, to smoothen the load curve and to reduce dispatching expensive power plants during peak time. In addition to that, when EVs are used as a battery to store energy from renewable energy sources such as solar and wind power, it gives cleaner energy to the grid.

In [31] a G2V control strategy is presented to minimize the impact on the grid. In this paper, two sets of programs were suggested to achieve two separate goals: (1) to achieve a desired aggregate load profile, and (2) to minimize the total number of on-off switchings of all EV charging profiles.

Different objectives of EV charging are discussed in [32], [33], [34] and [35]. The optimum EV charging schedule suggested in Ref. [32] was focused on minimizing the charging cost and energy cost from the substation point of view. It analyses the cost of charging from the grid point of view. Charging cost can be minimized if EVs are charged when energy costs are low. Ref. [33] focuses on minimizing the impact on the distribution transformer connected to the charging facility and the EV battery. Similar to [9], in [10] a methodology is proposed to perform charging 
focused on valley-filling of the transformer load curve. The authors have discussed how the algorithm updates its charging profile based on real-time changes in the load profile. It further describes a methodology to minimize loading of transformers to protect them from overloading. Ref. [35] proposed a methodology to provide grid support while improving the health of the EV battery. It explains the benefits of controlled EV charging to the grid and the battery, versus uncontrolled EV charging. All of the above research studies look at the grid operator's point of view and develop algorithms to optimize the grid impact.

An EV charging schedule can also be developed to minimize EV owner's costs, travel time or waiting time from the customer point of view [36], [37],[38],[39], [40] and [41].

In [36], a methodology is proposed to minimize the charging costs of an EV fleet taking into account spot prices and individual EV driving requirements. Rather than minimizing the charging cost of an individual EV consumer, the authors have illustrated how to minimize the total cost of an EV fleet by charging multiple EVs in parallel. EV waiting time at charging facilities, travel time to the charging facilities, and the total cost for the customer can be minimized with optimum EV charging scheduling [37],[38],[39]. Unlike the research discussed in [36], these studies focus on improving individual customer benefits, from the consumer's perspective. With these methodologies, customers have the ability to either reduce the charging cost or reduce the waiting time, based on their priorities. In addition to outside charging facilities, optimum EV charging schedules can be developed for EV charging at the household level with home energy management systems [40]. With this optimization method, home energy management system can decide the most optimum way to charge EVs, if there are multiple energy requirements at a house. In addition to charging from household electricity supply, an energy management system can be implemented for DC chargers in parking lots, as explained in 
paper [41]. Here authors suggest a methodology to charge EVs as quickly as possibly or to maximize EV owner's revenue by selling stored energy to the grid. All of these studies have different objectives based upon EV owner's perspective.

In [42], the authors propose a real-time EV scheduling algorithm as part of a building energy management system. The main objective of this study is to minimize the energy cost of the building where EVs are being charged.

From the above literature survey, it is clear that most of the research studies are available to minimize the charging cost from the consumer`s point of view or based on their impact on the connected grid. In this thesis, algorithms to minimize the cost of a merchant-owned EV charging facility from the charging facility owner's point of view are developed.

\subsection{Optimal Control of Discrete-Continuous Hybrid Systems}

Ref. [43], [44], [45] discuss optimal control of hybrid systems.

The optimization problem discussed in [43] was defined as a hybrid system consisting of a continuous function for ramping levels of production limits and a discrete function for up/down times of production. This hybrid system was solved using a Lagrangian relaxation and double dynamic programming method. The objective of optimizing the production planning is to minimize the production cost.

Another hybrid system with respect to EV energy management has been presented in [44]. The main objective was to optimize the energy management of an EV. This optimization problem is a hybrid system consisting of a discrete function for drive mode (electric or hybrid) and a continuous function for the torque split between the internal combustion engine and the motor/generator. A variation of the extremals algorithm was used to solve this hybrid optimal control problem. 
The hybrid system presented in [45], is focused on the steel manufacturing process to optimize product delivery time while meeting the quality requirement of steel strips. The main factors considered for this dynamic system are: number of processes, length, and arrival time of each steel strip. The backward recursive algorithm has been used to optimize the steel annealing process. It consists of a continuous function for the heating and cooling processes of the steel strip, and a discrete function for the arrival time of steel strips.

In terms of hybrid systems, this steel annealing process is similar to the process of EV charging at a charging facility. Both EV charging scheduling and the steel annealing process [45] have discrete arrival time intervals and continuous processes. EV charging is a continuous function and arrival time of each EV can be considered as a discrete input.

\subsection{Summary}

Many researchers have looked at optimizing electric vehicle charging to achieve various objectives. There are three main areas of interest: (1) the grid operator's perspective to minimize the grid impacts, (2) the customer's perspective to improve the customer benefits, and (3) building energy management. But none of the aforementioned studies discuss the function of the EV charging facility. Developing an EV charging schedule from the charging facility owner's point of view is the focus of this research.

There are several studies discussing optimal control of hybrid systems, and the nature of the hybrid system in the steel annealing process is analogous to the function of a single charger EV charging facility. 


\section{Chapter 3}

\section{Electrical Vehicle Charging for a Charging Facility with a Single Charger}

\subsection{Introduction}

EV charging can also be defined as a dynamic system, since it has a continuous charging function and discrete arrival times. However, this hybrid modeling approach results in a nonconvex non-differentiable optimization problem, which cannot be easily solved. To overcome this issue, the problem is decomposed into multiple smaller and simpler constrained convex optimization problems, which can be solved by classical techniques. The strategy to decompose the initial nonconvex problem into simpler convex problems is adapted from [45], to be employed in the optimization of the EV charging schedule for a charging facility with a single charger.

Current methods of finding an optimum schedule for EV charging do not address the issue of finding the minimum cost from the charging facility owner's perspective. Thus, the methodology proposed here aims to find an optimum schedule for EV charging with a minimum cost to the charging facility owner. Since the approach is nonlinear in nature, nonlinear factors can be directly added to the objective function.

\subsection{Nomenclature}

\subsubsection{Data}

$a_{k}=$ Arrival time of the $\mathrm{k}^{\text {th }}$ vehicle (hours)

$N=$ Number of vehicles coming to the charging station during the day

$E_{k}=$ Energy requirement of the $\mathrm{k}^{\text {th }}$ vehicle $(k W h)$

$K E=$ Electrcity rates $(\$ / \mathrm{kWh})$

$K P=$ Demand charge $(\$ / \mathrm{kW})$ 
$K W=$ Rate of penalty charge for waiting $\left(\$ /\right.$ hour $\left.^{2}\right)$

$b, c$ and $d=$ Constants of the loss factor

$P_{\max }=$ Maximum charging capacity of the charging station $(\mathrm{kW})$

\subsubsection{Problem variables}

$P M=$ Recorded Maximum power, during the day $(\mathrm{kW})$

$x_{k}=$ Charging completion time of the $\mathrm{k}^{\text {th }}$ vehicle (hours)

$P_{k}=$ Charging power of $\mathrm{k}^{\text {th }}$ vehicle $(\mathrm{kW})$

\subsubsection{Indices}

$\mathrm{k}=$ electric vehicle number

\subsection{Formulation}

This section presents the mathematical formulation of the convex optimization problem proposed for a charging facility with a single charger.

\subsubsection{Type of Costs Associated with the Objective Function}

Costs associated with EV charging depend on many factors. They can be described as follows.

\subsubsection{Energy cost}

Due to the complexity of nonlinear optimization algorithm, a flat rate of tariff was introduced to calculate the energy cost.

\subsubsection{Maximum demand charge}

It was calculated from the recorded maximum power at the charging facility during the day.

$$
\text { Demand charge }=\mathrm{KP} \cdot \mathrm{PM}
$$

where $\mathrm{KP}$ is the demand charge and PM is the recorded maximum demand. 


\subsubsection{Penalty for waiting}

A penalty charge was individually calculated for each EV based on its arrival time and exit time. Here it was considered that if a customer has to spend more time at the charging facility, the penalty charge for waiting is increasing in the form of a quadratic formula. Therefore, a nonlinear penalty charge was introduced. The penalty for waiting was calculated using the following formula:

$$
\text { Penalty for waiting }=K W \cdot \sum_{k=1}^{N}\left(x_{k}-a_{k}\right)^{2}
$$

\subsubsection{Loss of energy}

The cost associated with the loss of energy of a charging EV is considered under this factor. The loss can be varied based on the charging station efficiency. To reflect the variation of loss of energy, the following loss factor is introduced:

$$
\text { Loss Factor: } f L\left(P_{k}\right)=b+c \cdot P_{k}+d \cdot P_{k}^{2}
$$

where $b, c$ and $d$ are constants.

The cost of the loss for an individual $\mathrm{EV}$ is:

$$
\text { Cost of loss for an individual } E V=K W \cdot f L(P k) \cdot \text { Energy }
$$

The objective function can be defined with the equations shown in (3.1) - (3.4).

\subsubsection{Constraints Considered for the Objective Function}

The following constraints are included in the model:

- Charging power is limited by the maximum and minimum charging capability of the charging station and transformer which is connected to the charging station. 
- Charging finishing time of the $\mathrm{k}^{\text {th }} \mathrm{EV}$ depends on the duration of charging of the $\mathrm{k}^{\text {th }} \mathrm{EV}$ and the arrival of $\mathrm{k}^{\text {th }}$ vehicle or the charging finishing time of $(\mathrm{k}-1)^{\text {th }} \mathrm{EV}$.

\subsubsection{Objective Function}

The objective function to minimize the total cost can be written as the sum of energy costs (3.1), maximum demand charges (3.2), penalty for waiting (3.3) and loss penalty as a function of charging power (3.4) summed as below:

$$
f=\left[K E \cdot \sum_{k=1}^{N} E_{k}\right]+K P \cdot P M+\left[K W \cdot \sum_{k=1}^{N}\left(x_{k}-a_{k}\right)^{2}\right]+\left[K E \cdot \sum_{k=1}^{N} f L\left(P_{k}\right) \cdot E_{k}\right]
$$

\subsubsection{Constraints}

The loss factor is defined as below:

$$
f\left(P_{k}\right)=\text { loss factor }=b+c \cdot P_{k}+d \cdot P_{k}^{2}
$$

3.3.4.1 Recorded maximum power during the day

$$
P M=\max \left(P_{k}\right)
$$

3.3.4.2 Calculation of the charging completion time of the $\mathrm{k}^{\text {th }}$ vehicle

$$
x_{k}=\max \left(a_{k}, x_{k-1}\right)+\frac{E_{k}}{P_{k}}
$$

3.3.4.3 Maximum and minimum charging capacity of the charging station

$$
0 \leq P_{k} \leq P_{\max }
$$

Formulation (3.5) - (3.9) is solved using a backward recursive algorithm presented in the next section. 


\subsection{Obtaining the Optimum Solution}

The final optimum solution was given in the form of a matrix, which consists of finishing time and the average charging power of each EV. Based on these details the charging duration, waiting time, and charging power of an individual EV can be calculated.

Using this methodology, considering input data of arrival times and energy requirement of each $\mathrm{EV}$, finishing time and charging power of each EV can be obtained as outputs.

\subsubsection{Backward recursive algorithm}

This methodology is applied to minimize the cost of EV charging in this chapter. Consider $\mathrm{N}$ numbers of EVs are arriving to come to charging facility throughout the day. Following steps explain the algorithm to minimize the cost of EV charging.

Step 1: Minimize the objective function (3.5) assuming only $\mathrm{N}^{\text {th }} \mathrm{EV}$ arrives to the charging facility.

Step 2: Set variables $\mathrm{n}=\mathrm{N}-1$ and $\mathrm{k}=\mathrm{N}-1$.

Step 3: Minimize the objective function (3.5) for the combined system of $k^{\text {th }} E V$ to $n^{\text {th }} E V$.

Step 4: Check the status of the k value.

- If it is less than or equal to 1 , total EV charging cost is minimized and optimum solution is achieved in step 3 .

- If $\mathrm{k}$ value is higher than 1 go to step 5 .

Step 5: Compare 'n' value with the 'N'.

- If $\mathrm{n}$ is higher than or equal to $\mathrm{N}$, reassign the variables ' $\mathrm{n}$ ' and ' $\mathrm{k}$ ' as $\mathrm{k}=\mathrm{k}-1$ and $\mathrm{n}=\mathrm{k}-1$. Then proceed to step 3 .

- If $\mathrm{n}$ is less than $\mathrm{N}$, proceed to step 6 . 
Step 6: Compare $x_{n}$ with $a_{n+1}$.

- If $\mathrm{x}_{\mathrm{n}}$ is higher than $\mathrm{a}_{\mathrm{n}+1}$, reassign variable ' $\mathrm{n}$ ' as $\mathrm{n}=\mathrm{n}+1$ and go to step 3 .

- If $\mathrm{x}_{\mathrm{n}}$ is less than $\mathrm{a}_{\mathrm{n}+1}$ reassign the variables ' $\mathrm{n}$ ' and ' $\mathrm{k}$ ' as $\mathrm{k}=\mathrm{k}-1$ and $\mathrm{n}=\mathrm{k}-1$. Then proceed to Step 3.

This algorithm is explained in the flow chart shown in Figure 3.1 


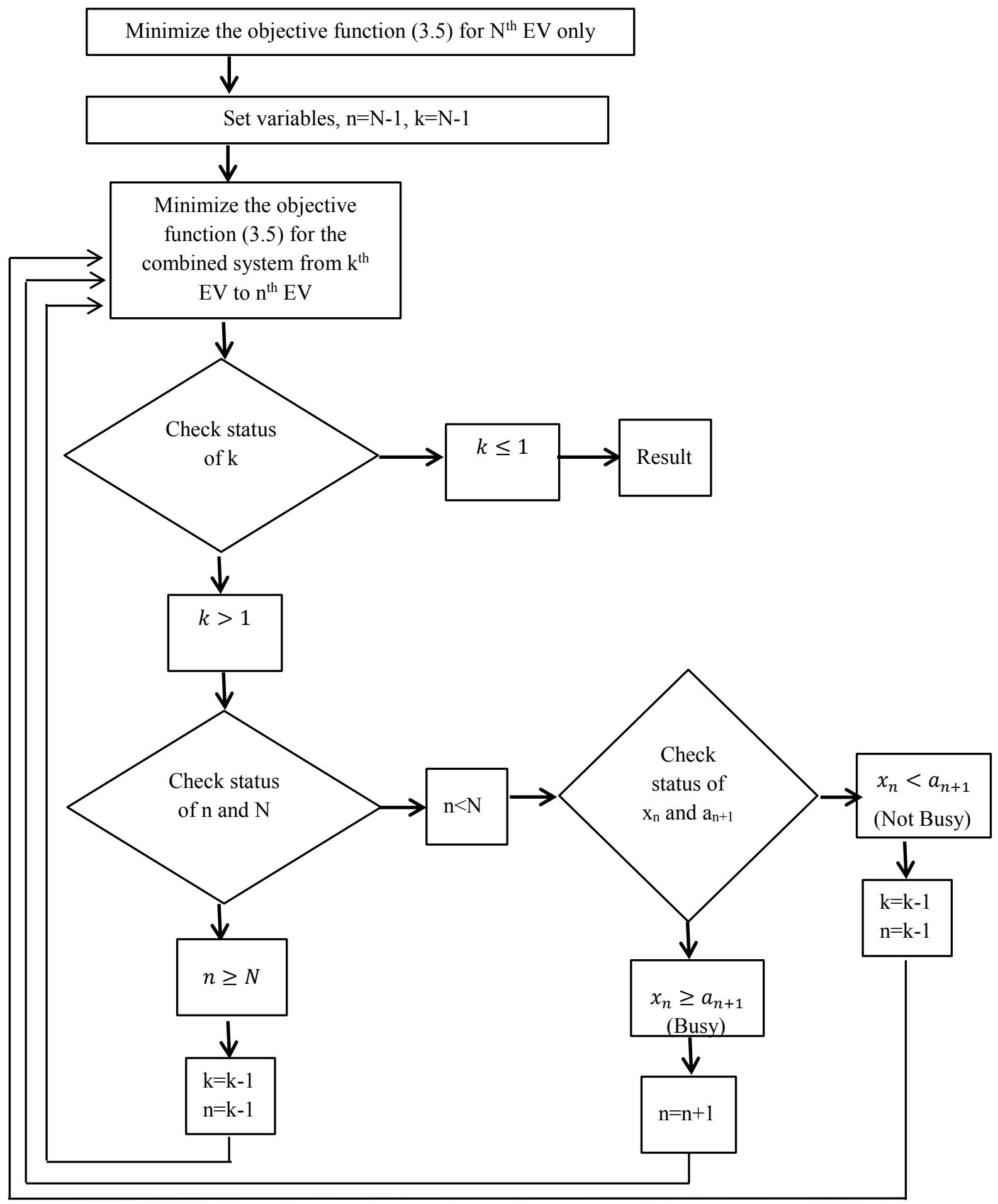

Figure 3.1 Flow chart of the backward recursive algorithm 


\subsection{Model Data and Test Results}

\subsubsection{Data}

The following data was used to analyze the proposed models.

\subsubsection{Charger's power limits}

It was assumed that the charger is a CHAdeMO type of a fast charger. So, the power limits of the charger are shown in (3.10):

$$
0 \leq P_{k} \leq 50 \mathrm{~kW}
$$

\subsubsection{Rate of penalty for waiting (KW)}

KW is assumed to be $7 \$$ hour. This value may be chosen by the merchant owner of the charging station infrastructure. Higher this value gets, lower will be the waiting time and it will help entice customers.

\subsubsection{Demand charge (KP)}

Based on the demand charge rate calculation of Toronto Hydro Corporation [46]:

(1) Transmission charge $=4.53 \$ / \mathrm{kW}$ (per peak $\mathrm{kW}$ per 30 days).

(2) Distribution charge $=6.34 \$ / \mathrm{kVA}$ (per peak $\mathrm{kW}$ per 30 days).

It was assumed that the charging facility has a power factor of 1.

$\therefore K P=4.53 \$ / k W+6.34 \$ / k W=10.87 \$ / k W($ per peak per 30 days) .

Hence, KP was assumed as $10.87 \$ / \mathrm{kW}$.

\subsubsection{Tariff structure (KE)}

Due to the complexity of the optimization problem, a flat rate of tariff was introduced to the algorithm. The Time of Use tariff imposed by the Ontario Energy Board was used to calculate an average value for the flat rate of tariff [46] :

$\mathrm{KE}=0.11 \$ / \mathrm{kWh}$. 


\subsubsection{Efficiency of the charger}

Based on the experimented results, the energy efficiency of CHAdeMO DC fast charger varies with the charging power as given in Table 3.1 below [47].

Table 3.1 Efficiency of CHAdeMO Charger

\begin{tabular}{|l|c|c|c|c|}
\hline P $(\mathrm{kW})$ & $\mathbf{1 6}$ & $\mathbf{2 2}$ & $\mathbf{4 3}$ & $\mathbf{5 0}$ \\
\hline Efficiency \% & $91.60 \%$ & $92.20 \%$ & $92.60 \%$ & $92.60 \%$ \\
\hline Loss \% & $8.40 \%$ & $7.80 \%$ & $7.40 \%$ & $7.40 \%$ \\
\hline
\end{tabular}

Since charging power is high in many cases, it can be assumed that charging efficiency is fixed. Approximated average energy efficiency of $\mathrm{CHAdeMO}=92.25 \%$. Hence, the following constants were chosen:

$$
b=0.0775, \quad c=0, \quad d=0
$$

The set of EVs arriving to the charging facility, with their battery capacities, energy requirements and arrival times, is shown in Table 3.2. This data set consists with busy and not busy periods.

Table 3.2 Arrivals of EV to the Charging Facility

\begin{tabular}{|r|l|c|c|c|}
\hline $\begin{array}{c}\text { Vehicle } \\
\text { No. }\end{array}$ & EV & $\begin{array}{c}\text { Battery Capacity (kWh) } \\
{[48],[49],[50],[51]}\end{array}$ & $\begin{array}{c}\text { Energy Requirement } \\
(\mathbf{k W h})\end{array}$ & $\begin{array}{c}\text { Arrival Time } \\
\mathbf{( h )}\end{array}$ \\
\hline 1 & Tesla-S & 90 & 80 & 12 \\
\hline 2 & Tesla-X & 90 & 50 & 14 \\
\hline 3 & Nissan LEAF & 30 & 24 & 17 \\
\hline 4 & Peugeot iOn & 16 & 14 & 20 \\
\hline
\end{tabular}




\subsubsection{Results}

Results for the optimum schedule obtained by the proposed model applied to the sample set of data discussed in the previous section are summarized in this section.

\subsubsection{Brute Force Method}

Base case was carried out without considering the backward recursive algorithm, a brute force method. Charging cost of each car was optimized individually. Base case was developed to compare the results between the base case and optimization with backward recursive algorithm. Under this methodology same objective function was minimized under same constraints except for, constraint (3.8). That constraint is replaced with following equation.

$$
\text { if } x_{i}>a_{i+1}, \quad x_{i}=a_{i+1}
$$

Final results are shown in Figure 3.2

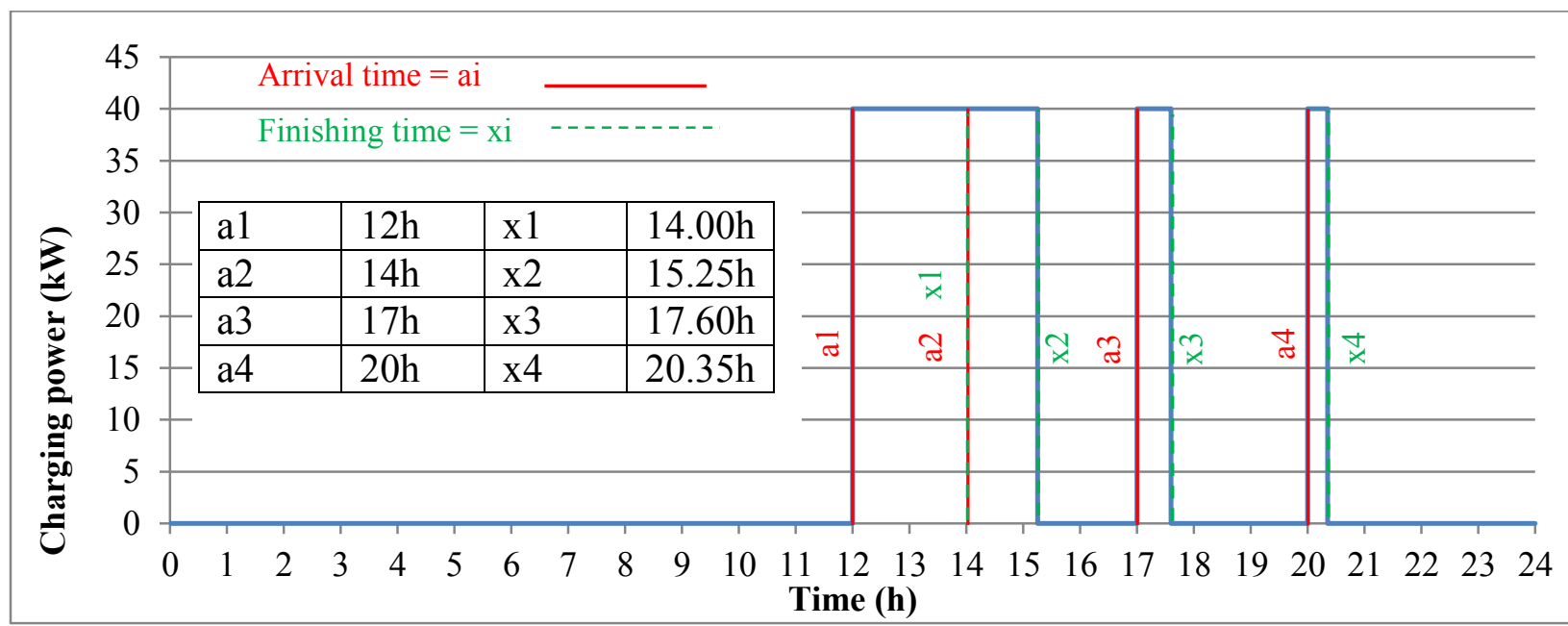

Figure 3.2 Time Line for $24 \mathrm{~h}$ (without backward recursive algorithm)

$$
\begin{array}{lll}
\text { Energy cost } & =0.11 \frac{\$}{\mathrm{kWh}} \cdot 168 \mathrm{kWh} & =\$ 18.48 \\
\text { Demand charge } & =\frac{10.87 \$}{\mathrm{~kW}} \cdot 40 \mathrm{~kW} & =\$ 434.8
\end{array}
$$


Penalty for waiting $=7 \frac{\$}{h^{2}} \cdot 6.045 h^{2} \quad=\$ 43.315$

Energy Loss $\quad=0.11 \frac{\$}{k W h} \cdot 13.02=\$ 1.43$

Total cost $\quad=\$ 497.03$.

\subsubsection{Optimization with Backward recursive algorithm}

Following methodology explains the optimization with backward recursive algorithm. The optimum mix of waiting time and charging power is set for each EV to obtain the minimum cost for the charging facility. The variation of the demand during the period under analysis is shown in Figure 3.3. One shall notice that in this initial case study it is considered that the four EVs arrive at different times.

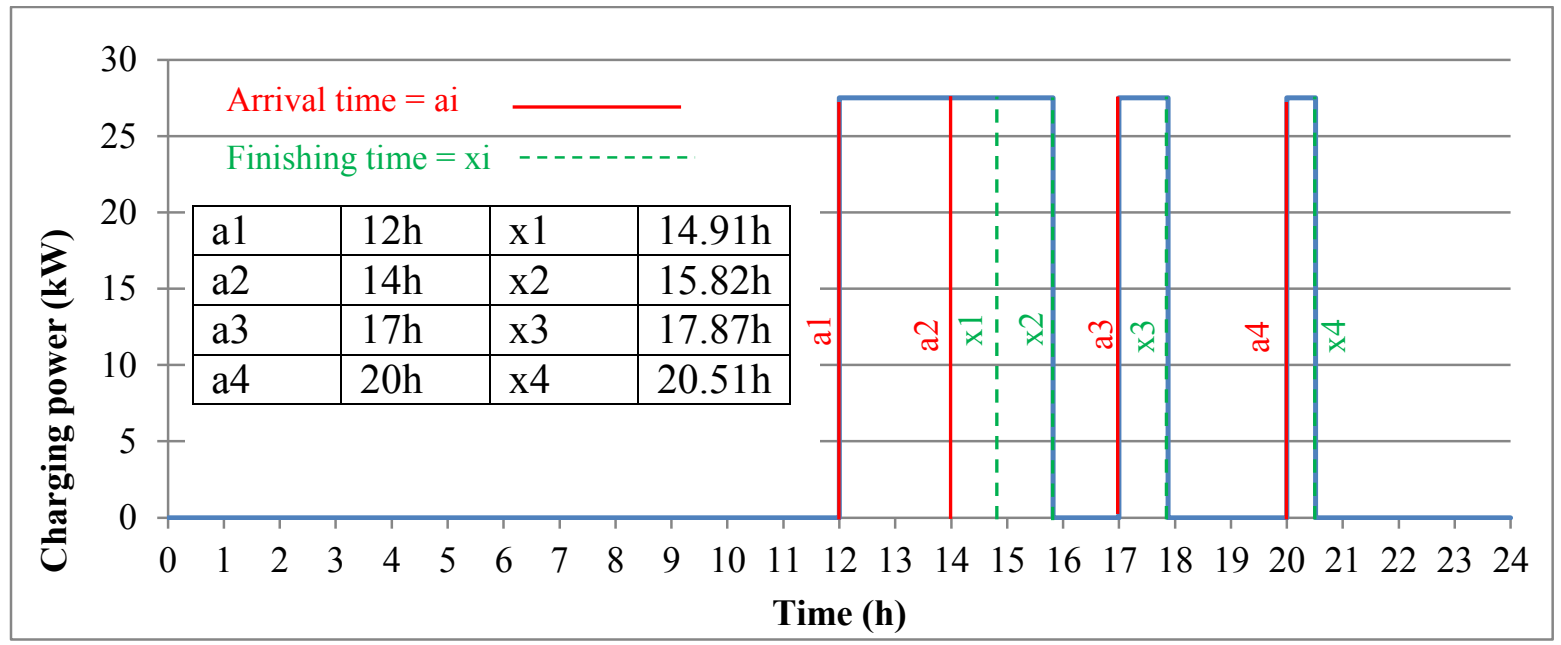

Figure 3.3 Time Line for 24h (with backward recursive algorithm)

Cost breakdown of the minimum cost is:

Energy cost $\quad=0.11 \frac{\$}{\mathrm{kWh}} \cdot 168 \mathrm{kWh}=\$ 18.48$

Demand charge $=10.87 \frac{\$}{\mathrm{~kW}} \cdot 27.5 \mathrm{~kW}=\$ 298.93$ 
Penalty for waiting $=7 \frac{\$}{h^{2}} \cdot 12.79 h^{2} \quad=\$ 89.53$

Energy Loss $\quad=0.11 \frac{\$}{k W h} \cdot 13.02=\$ 1.43$

Total cost $\quad=\$ 408.37$

\subsubsection{Comparison}

In the above sections 3.5.2.1 and 3.5.2.2, results are briefly described for charging patterns shown in Figure 3.2 and Figure 3.3. When the two methodologies are considered, it can be noticed that, backward recursive algorithm provides a minimum cost solution. Comparison of the charging pattern is shown in Figure 3.4

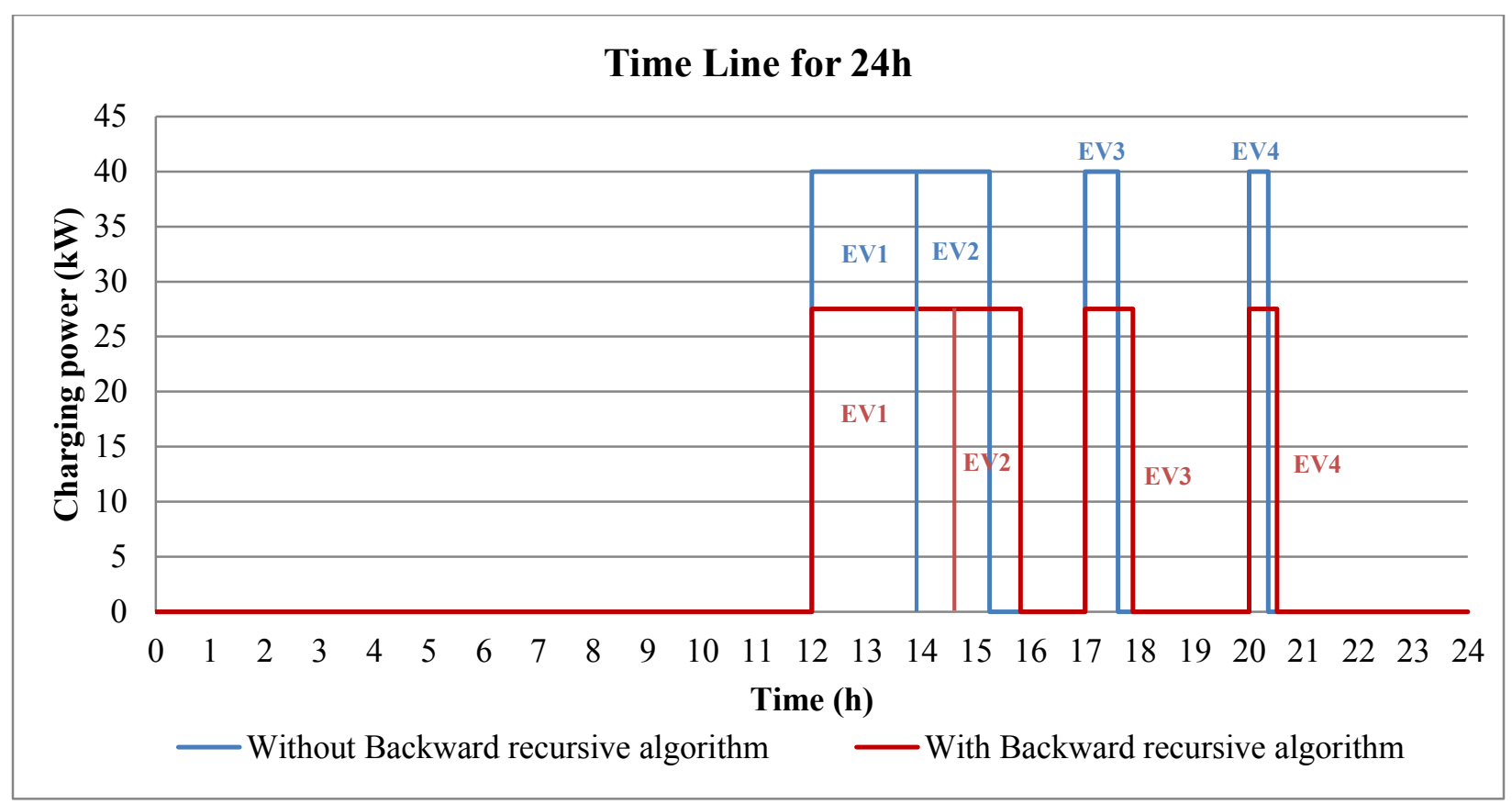

Figure 3.4 Time Line for $24 \mathrm{~h}$ (with and without backward recursive algorithm)

Sensitivity studies provided in the following section consider random (and conflicting) arrival times of EVs at the charging facility. 


\subsection{Sensitivity Analysis}

In order to get a clear understanding of the approach, further analysis has been carried out for a set of EVs. Generally, most of the data, which were described earlier, are fixed for the charging facility, so that the owner has no control over these variables except for the rate of penalty for waiting. Demand charge and energy cost are governed by the electric utility. Maximum charging power and the charger's efficiency are fixed for the charger. The charging facility owner only has control over the penalty charge for waiting. Total cost can be analyzed by varying the penalty for waiting. Sensitivity analysis has been carried out for the same set of data shown in Table 3.2 with different arrival times as shown in Table 3.3.

Table 3.3 Arrivals of EVs to the Charging Facility (For the Sensitivity Analysis)

\begin{tabular}{|c|c|c|}
\hline Vehicle & Energy requirement (kWh) & Arrival time (hour) \\
\hline 1 & 80 & 17.9 \\
\hline 2 & 50 & 18.5 \\
\hline 3 & 24 & 19.5 \\
\hline 4 & 14 & 20.6 \\
\hline
\end{tabular}

The optimum schedule was developed for different penalty factors such as KW=0.1 $\$ / \mathrm{h}^{2}, 7 \$ / \mathrm{h}^{2}$, $100 \$ / h^{2}, 200 \$ / h^{2}, 300 \$ / h^{2}$. The optimum schedules for the first four scenarios are shown in Figure 3.5. 


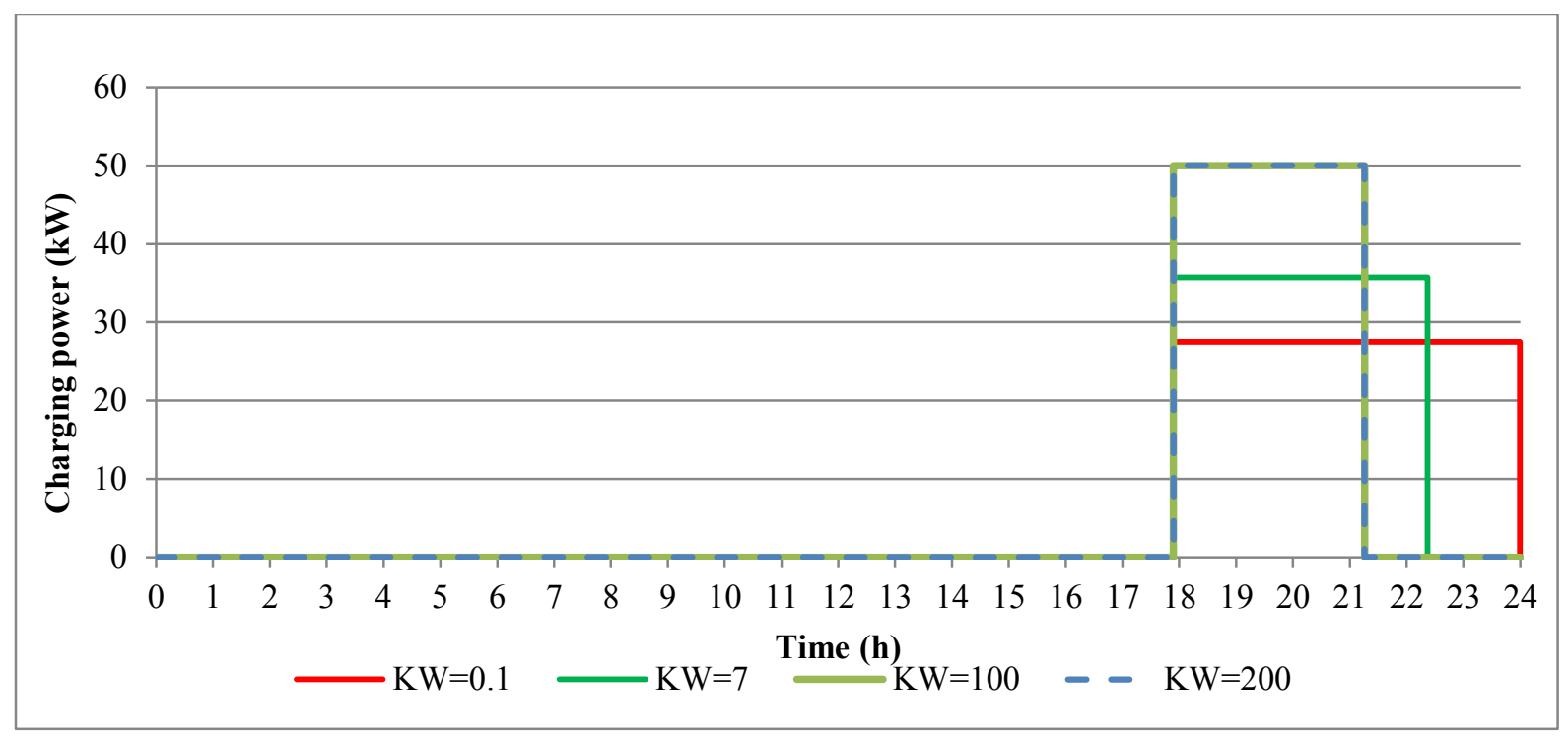

Figure 3.5 Optimum Charging Schedule at $\mathrm{KW}=0.1,7,100,200 \$ / \mathrm{h}^{2}$

It can be observed in Figure 3.5 that when penalty cost for waiting is increased, the waiting time of EVs is reduced, at the expense of higher charging power levels. In addition, after chargers reached the maximum power level $\left(50 \mathrm{~kW}\right.$, which is reached when $\left.\mathrm{KW}=100 \$ / \mathrm{h}^{2}\right)$, the behavior of the charging pattern was kept constant independent of the increase in KW. A summary of the results is shown in Table 3.4.

Table 3.4 Summary of the Sensitivity Analysis

\begin{tabular}{|c|c|c|c|c|c|}
\hline $\begin{array}{c}K W \\
\left(\$ / h^{2}\right)\end{array}$ & $\begin{array}{c}\text { Energy Cost } \\
\text { (\$) }\end{array}$ & $\begin{array}{c}\text { Demand } \\
\text { Charge (\$) }\end{array}$ & $\begin{array}{l}\text { Penalty } \\
\text { Cost (\$) }\end{array}$ & $\begin{array}{c}\text { Loss of Energy } \\
\text { (\$) }\end{array}$ & $\begin{array}{c}\text { Total Cost } \\
\text { (\$) }\end{array}$ \\
\hline 0.1 & 18.48 & 298.925 & 6.24 & 1.43 & 300.79 \\
\hline 7 & 18.48 & 388.43 & 173.07 & 1.43 & 581.41 \\
\hline 100 & 18.48 & 543.50 & 918.00 & 1.43 & 1481.41 \\
\hline 200 & 18.48 & 543.50 & 1836.00 & 1.43 & 2399.41 \\
\hline 300 & 18.48 & 543.50 & 2754.00 & 1.43 & 3317.41 \\
\hline
\end{tabular}


In this sensitivity study, the energy costs and the cost associated with loss of energy remain constant. Therefore, the variation in the total cost function depends only on the demand charge and the penalty cost for waiting. The resulting variation in these two parameters is revealed in Figure 3.6.

As the penalty cost for waiting increases, it is expected that the total waiting time observed in the 24 hours decreases. This result is indeed observed in the proposed formulation as shown in Table 3.5. The total waiting time is the sum of the charging time plus waiting time before charging starts, for all four EVs considered in the study.

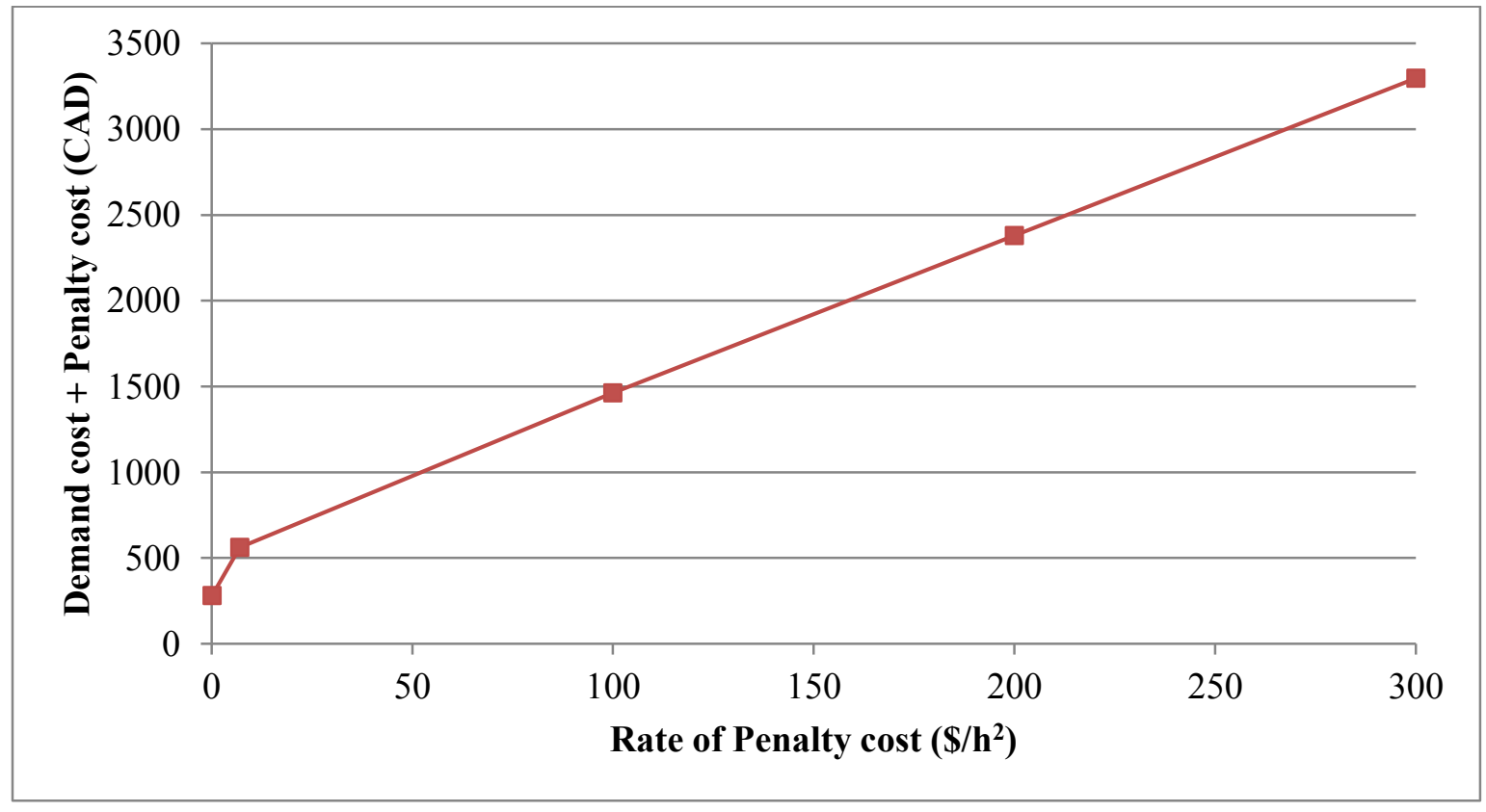

Figure 3.6 Demand Charge and Total Penalty Cost Variation for Different Values of the Penalty Rate for Waiting 
Table 3.5 Total Waiting Time for Each Value of the Penalty for Waiting (KW)

\begin{tabular}{|c|c|}
\hline $\boldsymbol{K} \boldsymbol{W}\left(\mathbf{\$} / \mathbf{h}^{\mathbf{2}}\right)$ & Total Waiting Time (h) \\
\hline 0.1 & 15.6 \\
\hline 7 & 9.76 \\
\hline 100 & 5.74 \\
\hline 200 & 5.74 \\
\hline 300 & 5.74 \\
\hline
\end{tabular}

This conflicting relationship between the demand charge and the total waiting time, for different values of the penalty rate for waiting (KW) is shown in Figure 3.7.

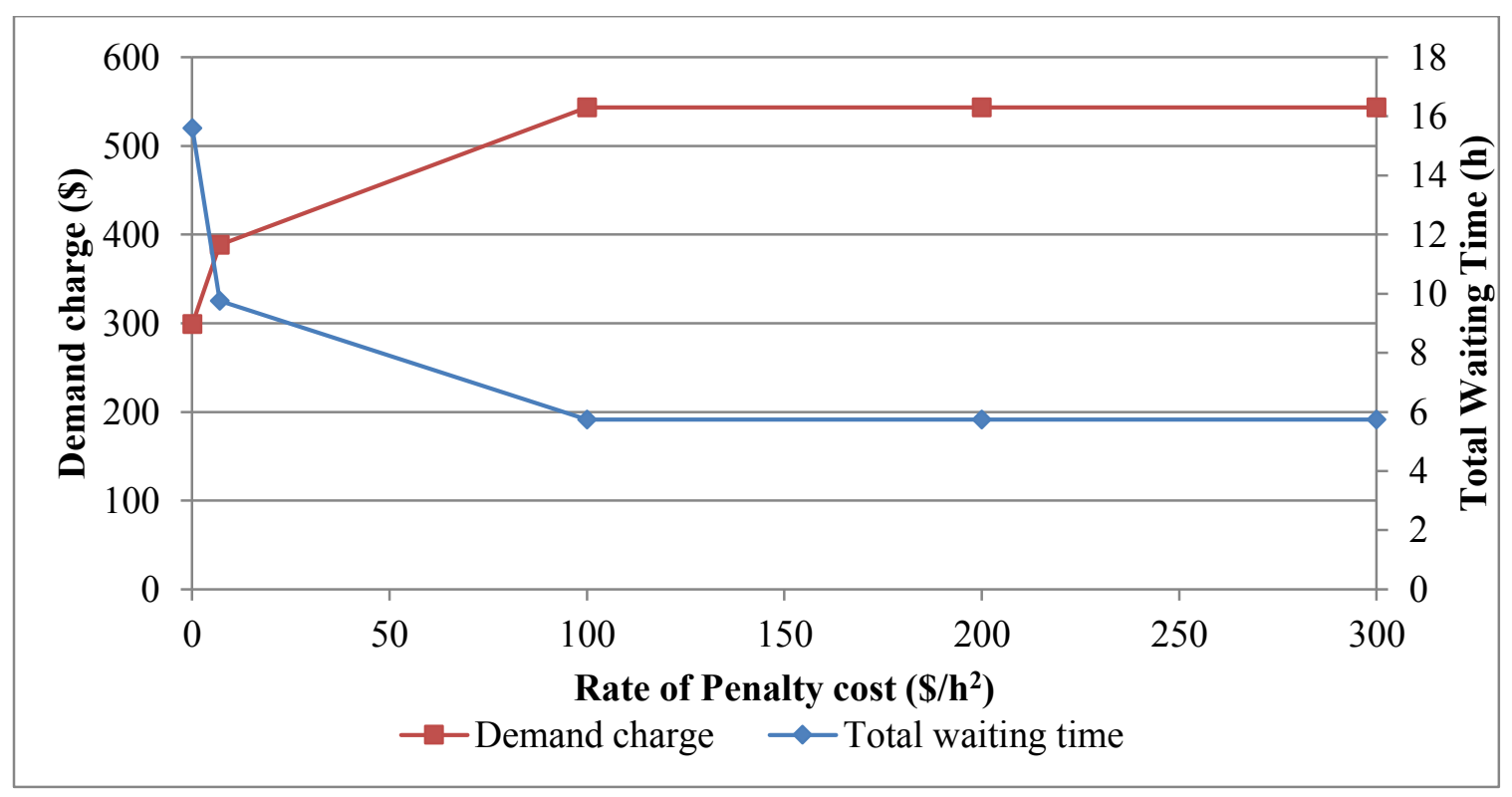

Figure 3.7 Demand Charge Variation for Different Penalty Rates

As the penalty rate $\mathrm{KW}$ increases, the algorithm tends to reduce the waiting time and charge the EV as fast as possible. However, due to the constraint of maximum charging capacity of the fast charger, the maximum charging power is limited to $50 \mathrm{~kW}$. As a result, it can be observed in Figure 3.7 that the demand charge saturates after a certain value of $\mathrm{KW}$. After this particular 
point, the only reason for the cost increment is the rate of penalty cost for waiting. Since all the values are fixed after saturation, waiting time is also fixed.

The current methods proposed in the technical literature have addressed this issue from the customer point of view and based on grid impact [22] - [40]. Since approaching the problem from the charging facility owner's point of view is a novel idea, this methodology cannot be fairly compared with existing approaches.

\subsection{Summary}

In this chapter, with charging of electric vehicles being a hybrid system, an optimization algorithm was derived from [45] and was used to optimize the schedule of electric vehicle charging with a single charger. Due to the complexity of the objective function, a flat rate of electricity tariff was assumed for the objective function.

The objective function consisted of different cost types such as energy cost, maximum demand charge, and penalty for waiting. Loss of energy was minimized under the constraints of loss factor, maximum power, and the relationship between the completion time and arrival time of two consecutive vehicle arrivals. Since it is a hybrid system, it leads towards a nonconvex and non-differentiable problem, so it was disintegrated into multiple smaller and simple constrained convex optimization problems. With the derived convex model proposed, an optimum schedule for electric vehicle charging was determined.

The optimum solution was given as a matrix and consists of finishing time and average charging power of each EV. Since the arrival time and energy requirement were given in the data, the charging time and idle time of each EV can be calculated.

An analysis for a sample data set and a sensitivity analysis have been carried out to analyze the system and results were discussed through tables and charts. The penalty for waiting time was 
chosen as the variable for the sensitivity analysis as it is the only factor that charging facility owner can control. Results were obtained and discussed in this chapter. 


\section{Chapter 4}

\section{Electrical Vehicle Charging for a Charging Facility with Multiple Chargers}

\subsection{Introduction}

In Chapter 3, a nonlinear approach to minimize the cost of EV charging at a merchant-owned charging facility with a single charger was proposed, developed and demonstrated on a sample case. However, such methodology cannot be used for a charging facility with multiple chargers due to problem complexity and the inability to determine which EV will go to which charger within the charging facility. To address this challenge, a discrete linear approach to minimize the cost of EV charging in a merchant-owned charging station with multiple chargers is proposed in this chapter.

In this chapter, an optimal EV scheduling formulation and algorithm for a merchant-owned charging facility with multiple chargers is proposed from the merchant-owned EV station's perspective. It is created as a mixed-integer linear formulation. The MOSEK optimization toolbox in MATLAB was used to optimize this linear formulation.

\subsection{Nomenclature}

\section{Data}

$N C=$ Number of charging stations

$N E=$ Number of Electrical Vehicles

$N T=$ Number of total time segments

Energy $_{e}=$ Energy requirement of Electric vehicle ' $\mathrm{e}^{\prime}(\mathrm{kWh})$

$\Delta t=$ Duration of an individual time segment in hours(hour)

$K E_{t}=$ Electricity rates $(\$ / \mathrm{kWh})$

$K P=$ Demand charge $(\$ / \mathrm{kW})$ 
$K W=$ Rate of penatly charge for waiting $(\$ /$ hour $)$

$N=$ Number of vehicles coming to the charging station during the day

$a_{e}=$ Arrival time of the $\mathrm{e}^{\text {th }}$ vehicle (hours)

$P_{\max }=$ Maximum charging capacity of each charging station $(\mathrm{kW})$

$P M_{\max }=$ Maximum power capacity of the transformer connected to all chargers (kW)

\section{Problem variables}

$E_{e}=$ Energy cost of Electric vehicle ' $\mathrm{e}^{\prime}(\$)$

$T_{e}=$ Total waiting time of each $\mathrm{EV}^{\prime} \mathrm{e}^{\prime}$ (hour)

$P M=$ Recorded maximum power, during the day $(\mathrm{kW})$

\section{3-Dimensional Variables}

$\mathrm{U}_{\text {tec }}=$ Status of electric vehicle ' $\mathrm{e}$ ' getting charged at charger ' $c$ ', at time slot ' $\mathrm{t}$ '

$S_{\text {tec }}=$ Status when an EV 'e' starts charging, at charger ' $c$ ', at time slot ' $t$ '

$P_{\text {tec }}=$ Charging power of electric vehicle ' $e$ ' getting charged at charging station ' $c$ ', at time slot ' $\mathrm{t}$ '

\section{Indices}

$\mathrm{e}=$ Electric vehicle number

$\mathrm{t}=$ Time segment number

$\mathrm{c}=$ Charger number 


\subsection{Formulation}

The objective function and constraints can be explained as follows.

\subsubsection{Type of Costs Associated with the Objective Function}

Costs associated with EV charging depend on many factors.

\subsubsection{Energy cost}

Time of Use (TOU) tariff was introduced to the linear optimization algorithm. Time of Use rates

for small business given by the Ontario Energy Board have been used for the algorithm to calculate the energy cost [46]. Tariff structures from other jurisdictions can be easily implemented in the proposed formulation.

\subsubsection{Maximum demand charge}

The maximum demand charge is the cost calculated based on the maximum demand (kW) used to charge EVs during the day. When there are multiple chargers available in the charging facility, the charging powers of all the chargers should be added together at the corresponding time, to obtain the maximum demand during the day. Mathematically, the maximum demand charge is:

$$
\text { Demand charge }=\mathrm{KP}\left(\frac{\$}{\mathrm{~kW}}\right) \cdot \mathrm{PM}(\mathrm{kW})
$$

where 'KP' represents demand charge.

\subsubsection{Penalty for waiting}

There is a penalty cost associated with each EV for the duration of time when the EV is waiting in the charging facility (this includes both the queueing time and charging time). A linear form of penalty charge has been imposed on the waiting time of EVs. 


\subsubsection{Constraints Considered for the Objective Function}

- Charging power is limited by the maximum and minimum charging capability of the charger and the transformer which is connected to all chargers.

- There is only one EV being charged per charger in a given time.

- Each EV should be charged for only one continuous period of time.

- None of the EVs should be charged before arriving to the charging facility

\subsubsection{Objective Function}

The objective function is to minimize the sum of energy costs, maximum demand charges and penalty for waiting, as below;

$$
f=\sum_{e=1}^{N E} E_{e}+K P \cdot P M+K W \cdot \sum_{e=1}^{N E} T_{e}
$$

\subsubsection{Constraints}

To ensure there is only one car at a charging point in a given time period, the following constraints are defined.

$$
\sum_{c=1}^{N C} U_{t e c} \leq 1, \forall t ; \forall e ; \quad \sum_{\mathrm{e}=1}^{\mathrm{NE}} \mathrm{U}_{\mathrm{tec}} \leq 1, \forall \mathrm{t} ; \forall \mathrm{c} ;
$$

where $0 \leq \mathrm{U}_{\text {tec }} \leq 1$.

To ensure that an electric vehicle will charge continuously at one charging point, the following constraint is defined:

$$
S_{t e c} \geq U_{t e c}-U_{(t-1) e c} ; \quad 0 \leq S_{t e c} \leq 1 ; \quad \sum_{c}^{N C} \sum_{t}^{N T} S_{t e c}=1
$$

To calculate the charging power of all Electric Vehicles at a given time slot ' $t$ ', the following constraint is defined: 


$$
\begin{gathered}
\sum_{e=1}^{N E} \sum_{c=1}^{N C} P_{t e c}=P D_{t} \\
P M=\max \left(P D_{t}\right)
\end{gathered}
$$

Boundary power values of the transformer, which is connected to all chargers is defined below

$$
0 \leq P M \leq P M_{\max }
$$

The maximum and minimum charging capacity of each charger is constrained as below:

$$
0 \leq P_{\text {tec }} \leq U_{\text {tec }} \cdot P_{\max }
$$

To ensure energy requirement is satisfied for EV 'e', the following constraint is defined:

$$
\sum_{c=1}^{N C} \sum_{t=1}^{N T} P_{t e c} \cdot[\Delta t]=E_{e}
$$

where, $\Delta t=\frac{5}{60}=0.0833$ hours

To ensure an Electric Vehicle will not be charged before its arriving time, the following constraint is defined:

$$
U_{t e c}=0 \quad \forall t<a_{i} ; \forall c ; \forall e ;
$$

The total waiting time for electric vehicle ' $\mathrm{e}$ ' is defined as below:

$\mathrm{T}_{\mathrm{e}}$ (Total waiting time $)=$ idle time + charging time

$$
T_{e}=\left[\Delta t \cdot \sum_{t=1}^{N T} \sum_{c=1}^{N C} S_{t e c}\right]-a_{e}+\left[\Delta t \cdot \sum_{t=1}^{N T} \sum_{c=1}^{N C} U_{t e c}\right]
$$

Calculation of energy cost for each EV ' $\mathrm{e}$ ' $\left(\mathrm{E}_{\mathrm{e}}\right)$ is as below: 


$$
E_{e}=\sum_{c=1}^{N C} \sum_{t=1}^{N T} K E_{t} \cdot P_{t e c} \cdot \Delta t
$$

The formulation (4.1) - (4.11) is a mixed integer linear optimization challenge. It can be solved by using a commercial solver.

\subsection{Solution Process}

Optimization was completed with three dimensional matrices U, P and S, which were defined in the formulation. Each of these three 3-dimensional matrices consists of three axes (time, charger and EV). Due to the complexity of the system, the timeline was divided into small time segments. Waiting time and charging time were given in the number of time segments. In this approach, each time segment equals 5 minutes or 0.0833 hours. The structure of the 3 dimensional matrices $\mathrm{U}, \mathrm{P}$ and $\mathrm{S}$ can be visualized as in Figure 4.1.

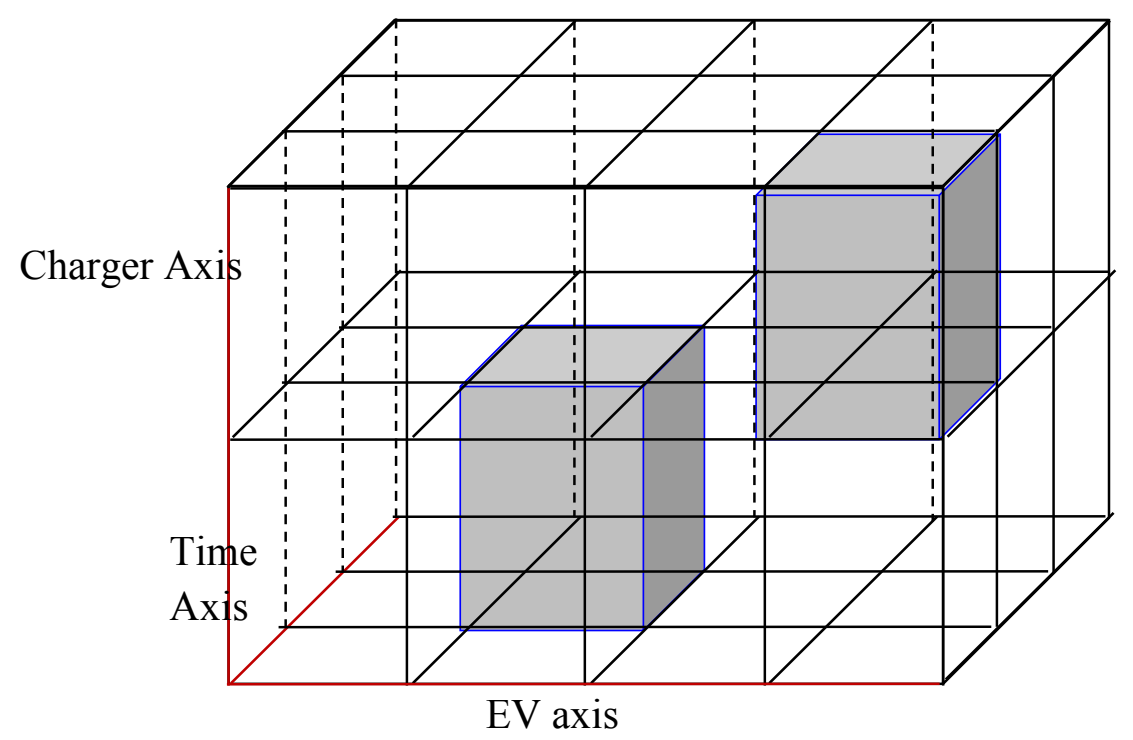

Figure 4.1 View of 3-Dimentional Matrices

These three 3-dimensional matrices will provide the values for each of the following variables at the minimum cost: 
- Matrix U identifies the charging duration of each EV

- Matrix S identifies each EV's starting time of charging

- Matrix P provides the charging power of each EV at each charging point for all the time intervals

- Recorded maximum power at the charging facility for each time segment during the day

- Recorded maximum power during the day

- Total waiting time of each EV (queueing time and charging time)

- Calculation of energy cost of each EV by using TOU tariff

Using this methodology, when arrival times and energy requirements of each EV are given as inputs, waiting time, charger designation, and charging power of each EV can be obtained as outputs.

\subsection{Data and Test Results}

\subsubsection{Data}

Set of data considered for the algorithm, is as follows

\subsubsection{Transformer power limits}

Power ratings for transformers are considered, based on the ratings given by $\mathrm{ABB}$ medium distribution transformer manufactures [52]. There can be distribution transformers ranging from $15 \mathrm{kVA}$ to 10MVA [53]. In this case, the power factor of the transformer is assumed as 0.8 . Here it was assumed that the charging facility is connected to a transformer with a power rating of $1000 \mathrm{kVA}$. The transformer power limits are assumed as: $\mathrm{P}_{\max }=800 \mathrm{~kW}$ and $\mathrm{P}_{\min }=0 \mathrm{~kW}$. 


\subsubsection{Power limits of chargers}

In this algorithm, it was assumed all chargers have the charging power up to $50 \mathrm{~kW}$. Hence, power limits of the EV chargers are $\mathrm{P}_{\max }=50 \mathrm{~kW}$ and $\mathrm{P}_{\min }=0 \mathrm{~kW}$.

\subsubsection{Rate of penalty for waiting $(K W)$}

The penalty for waiting is the discount given the merchant to the EV owners. The higher the penalty, lower are the charging costs for EV owners and lesser are the profits for the merchant owners of the charging facility. In this work, $K W$ is assumed to be $7 \$ / \mathrm{h}$. Later, a sensitivity analysis is completed to explain the effect of this factor on the results.

\subsubsection{Demand charge (KP)}

Demand charges were obtained from Toronto Hydro Corporation [46] as below:

(1) Transmission charge $=4.53 \$ / \mathrm{kW}$ (per peak $\mathrm{kW}$ per 30 days).

(2) Distribution charge $=6.34 \$ / \mathrm{kVA}$ (per peak $\mathrm{kW}$ per 30 days).

By assuming the charging facility is at unity power factor, distribution charges can be approximated to $6.34 \$ / \mathrm{kW}$ and the total demand charge $\mathrm{KP}$ will be $4.53 \$ / \mathrm{kW}+6.34 \$ / \mathrm{kW}=$ $10.87 \$ / \mathrm{kW}$ (per peak $\mathrm{kW}$ per 30 days).

\subsubsection{Tariff structure (KE)}

It is defined based on the Time of Use tariff imposed by the Ontario Energy Board [46]:

- On peak: $0.157 \$ / \mathrm{kWh}$ during $11 \mathrm{am}-5 \mathrm{pm}$.

- $\quad$ Mid peak: $0.113 \$ / \mathrm{kWh}$ during $7 \mathrm{am}-11 \mathrm{am}$ and $5 \mathrm{pm}$ to $7 \mathrm{pm}$.

- Off peak: $0.077 \$ / \mathrm{kWh}$ during $7 \mathrm{pm}$ to $7 \mathrm{am}$.

\subsubsection{Size of a time segment $(\Delta t)$}

In this work, $\Delta t$ is set as 0.0833 hours or 5 minutes. 


\subsubsection{Number of chargers (NC)}

For the purpose of this study, the number of chargers at the charging facility is assumed to be 2 .

\subsubsection{Test Results}

Initially, to illustrate the method, a sample optimization run is carried out by considering the presence of two charging stations in the charging facility. The results obtained for the data set shown in Table 4.1, are presented in Figure 4.2 and Table 4.5. Resultant U, S and P matrices are shown in Table 4.2, Table 4.3 and Table 4.4.

Table 4.1 Arrivals of EVs to the Charging Facility

\begin{tabular}{|r|l|c|c|c|}
\hline $\begin{array}{c}\text { Vehicle } \\
\text { No. }\end{array}$ & EV & $\begin{array}{c}\text { Battery Capacity } \\
\mathbf{( k W h )} \\
{[48],[49],[50],[51]}\end{array}$ & $\begin{array}{c}\text { Energy Requirement } \\
(\mathbf{k W h})\end{array}$ & Arrival Time \\
\hline 1 & Tesla-S & 90 & 80 & 10 \\
\hline 2 & Tesla-X & 90 & 50 & 14 \\
\hline 3 & Nissan LEAF & 30 & 24 & 20 \\
\hline 4 & Peugeot iOn & 16 & 14 & 17 \\
\hline
\end{tabular}




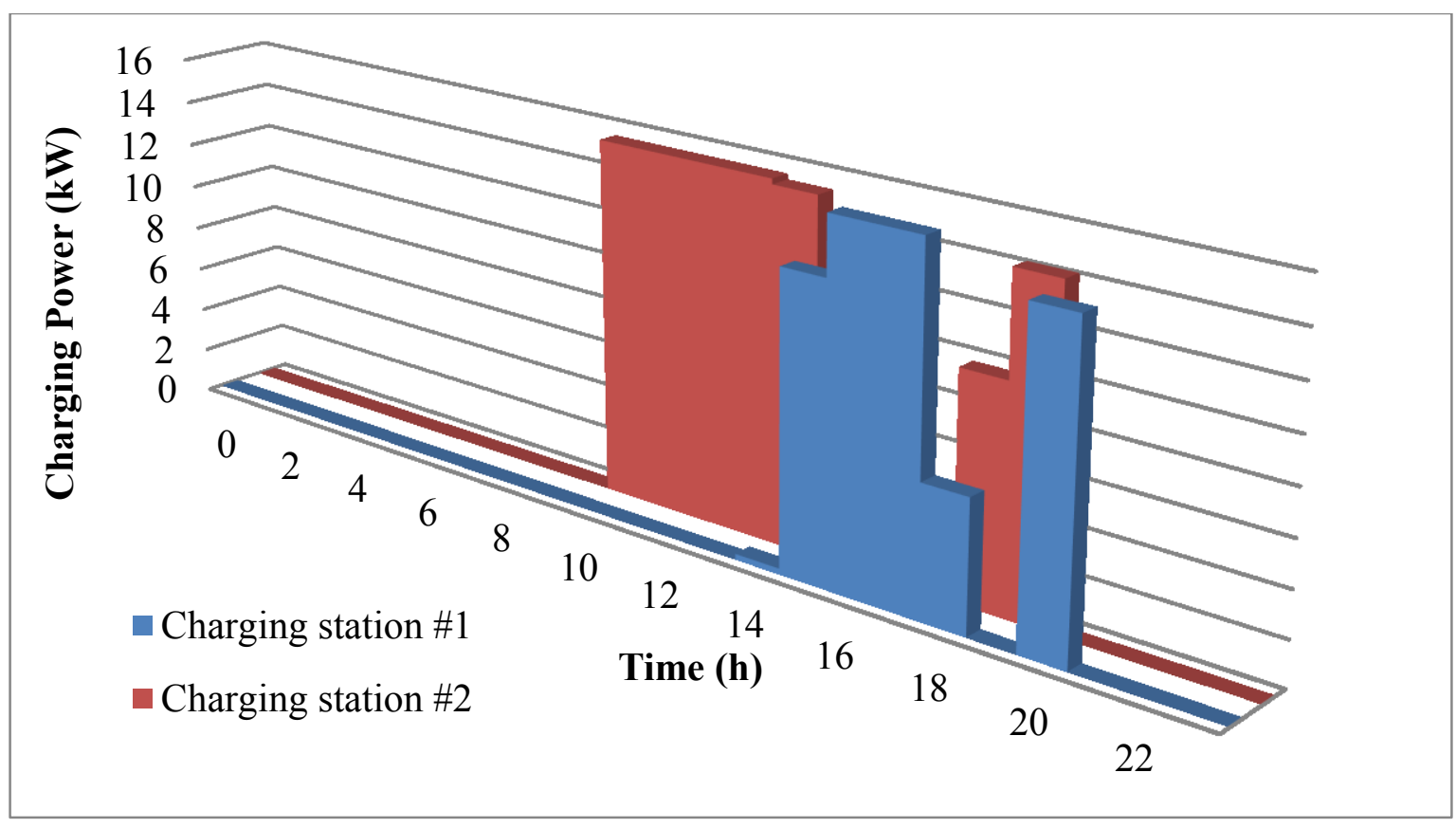

Figure 4.2 Time Line for $24 \mathrm{~h}$ for Charger \#1 and \#2 
Table 4.2 Matrix $U$ for charger \#1 and charger \#2

\begin{tabular}{|c|c|c|c|c|}
\hline \multicolumn{5}{|c|}{ Matrix $U$ for charger \#1 } \\
\hline Time (h) & EV \#1 & EV \#2 & $\mathrm{EV} \# 3$ & $\mathrm{EV} \# 4$ \\
\hline 0 & 0 & 0 & 0 & 0 \\
\hline 1 & 0 & 0 & 0 & 0 \\
\hline 2 & 0 & 0 & 0 & 0 \\
\hline 3 & 0 & 0 & 0 & 0 \\
\hline 4 & 0 & 0 & 0 & 0 \\
\hline 5 & 0 & 0 & 0 & 0 \\
\hline 6 & 0 & 0 & 0 & 0 \\
\hline 7 & 0 & 0 & 0 & 0 \\
\hline 8 & 0 & 0 & 0 & 0 \\
\hline 9 & 0 & 0 & 0 & 0 \\
\hline 10 & 0 & 0 & 0 & 0 \\
\hline 11 & 0 & 0 & 0 & 0 \\
\hline 12 & 0 & 0 & 0 & 0 \\
\hline 13 & 0 & 0 & 0 & 0 \\
\hline 14 & 0 & 1 & 0 & 0 \\
\hline 15 & 0 & 1 & 0 & 0 \\
\hline 16 & 0 & 1 & 0 & 0 \\
\hline 17 & 0 & 1 & 0 & 0 \\
\hline 18 & 0 & 1 & 0 & 0 \\
\hline 19 & 0 & 0 & 0 & 0 \\
\hline 20 & 0 & 0 & 0 & 1 \\
\hline 21 & 0 & 0 & 0 & 0 \\
\hline 22 & 0 & 0 & 0 & 0 \\
\hline 23 & 0 & 0 & 0 & 0 \\
\hline
\end{tabular}

\begin{tabular}{|c|c|c|c|}
\hline \multicolumn{4}{|c|}{ Matrix $U$ for charger \#2 } \\
\hline EV \#1 & EV \#2 & EV \#3 & $\mathrm{EV} \# 4$ \\
\hline 0 & 0 & 0 & 0 \\
\hline 0 & 0 & 0 & 0 \\
\hline 0 & 0 & 0 & 0 \\
\hline 0 & 0 & 0 & 0 \\
\hline 0 & 0 & 0 & 0 \\
\hline 0 & 0 & 0 & 0 \\
\hline 0 & 0 & 0 & 0 \\
\hline 0 & 0 & 0 & 0 \\
\hline 0 & 0 & 0 & 0 \\
\hline 0 & 0 & 0 & 0 \\
\hline 1 & 0 & 0 & 0 \\
\hline 1 & 0 & 0 & 0 \\
\hline 1 & 0 & 0 & 0 \\
\hline 1 & 0 & 0 & 0 \\
\hline 1 & 0 & 0 & 0 \\
\hline 1 & 0 & 0 & 0 \\
\hline 0 & 0 & 0 & 0 \\
\hline 0 & 0 & 0 & 0 \\
\hline 0 & 0 & 1 & 0 \\
\hline 0 & 0 & 1 & 0 \\
\hline 0 & 0 & 0 & 0 \\
\hline 0 & 0 & 0 & 0 \\
\hline 0 & 0 & 0 & 0 \\
\hline 0 & 0 & 0 & 0 \\
\hline
\end{tabular}


Table 4.3 Matrix $S$ for charger \#1 and charger \#2

\begin{tabular}{|r|r|r|r|r|}
\hline \multicolumn{5}{|c|}{ Matrix S for charger \#1 } \\
\hline & & & & \\
Time (h) & & & & \\
\hline 0 & 0 & 0 & 0 & 0 \\
\hline 1 & 0 & 0 & 0 & 0 \\
\hline 2 & 0 & 0 & 0 & 0 \\
\hline 3 & 0 & 0 & 0 & 0 \\
\hline 4 & 0 & 0 & 0 & 0 \\
\hline 5 & 0 & 0 & 0 & 0 \\
\hline 6 & 0 & 0 & 0 & 0 \\
\hline 7 & 0 & 0 & 0 & 0 \\
\hline 8 & 0 & 0 & 0 & 0 \\
\hline 9 & 0 & 0 & 0 & 0 \\
\hline 10 & 0 & 0 & 0 & 0 \\
\hline 11 & 0 & 0 & 0 & 0 \\
\hline 12 & 0 & 0 & 0 & 0 \\
\hline 13 & 0 & 0 & 0 & 0 \\
\hline 14 & 0 & 1 & 0 & 0 \\
\hline 15 & 0 & 0 & 0 & 0 \\
\hline 16 & 0 & 0 & 0 & 0 \\
\hline 17 & 0 & 0 & 0 & 0 \\
\hline 18 & 0 & 0 & 0 & 0 \\
\hline 19 & 0 & 0 & 0 & 0 \\
\hline 20 & 0 & 0 & 0 & 1 \\
\hline 21 & 0 & 0 & 0 & 0 \\
\hline 22 & 0 & 0 & 0 & 0 \\
\hline 23 & 0 & 0 & 0 & 0 \\
\hline & & & & \\
\hline
\end{tabular}

\begin{tabular}{|r|r|r|r|}
\hline \multicolumn{4}{|c|}{ Matrix S for charger \#2 } \\
\hline & & & \\
EV \#1 & EV \#2 & EV \#3 & EV \#4 \\
& & & \\
\hline 0 & 0 & 0 & 0 \\
\hline 0 & 0 & 0 & 0 \\
\hline 0 & 0 & 0 & 0 \\
\hline 0 & 0 & 0 & 0 \\
\hline 0 & 0 & 0 & 0 \\
\hline 0 & 0 & 0 & 0 \\
\hline 0 & 0 & 0 & 0 \\
\hline 0 & 0 & 0 & 0 \\
\hline 0 & 0 & 0 & 0 \\
\hline 0 & 0 & 0 & 0 \\
\hline 1 & 0 & 0 & 0 \\
\hline 0 & 0 & 0 & 0 \\
\hline 0 & 0 & 0 & 0 \\
\hline 0 & 0 & 0 & 0 \\
\hline 0 & 0 & 0 & 0 \\
\hline 0 & 0 & 0 & 0 \\
\hline 0 & 0 & 0 & 0 \\
\hline 0 & 0 & 0 & 0 \\
\hline 0 & 0 & 1 & 0 \\
\hline 0 & 0 & 0 & 0 \\
\hline 0 & 0 & 0 & 0 \\
\hline 0 & 0 & 0 & 0 \\
\hline 0 & 0 & 0 & 0 \\
\hline 0 & 0 & 0 & 0 \\
\hline
\end{tabular}


Table 4.4 Matrix $P$ for charger \#1 and charger \#2

\begin{tabular}{|c|c|c|c|c|}
\hline \multicolumn{5}{|c|}{ Matrix $\mathrm{P}$ for charger $\# 1$} \\
\hline $\begin{array}{l}\text { Time } \\
\text { (h) }\end{array}$ & $\begin{array}{c}\text { EV1 } \\
(\mathrm{kW})\end{array}$ & $\begin{array}{c}\text { EV2 } \\
(\mathrm{kW})\end{array}$ & $\begin{array}{l}\text { EV3 } \\
(\mathrm{kW})\end{array}$ & $\begin{array}{c}\text { EV4 } \\
(\mathrm{kW})\end{array}$ \\
\hline 0 & 0 & 0 & 0 & 0 \\
\hline 1 & 0 & 0 & 0 & 0 \\
\hline 2 & 0 & 0 & 0 & 0 \\
\hline 3 & 0 & 0 & 0 & 0 \\
\hline 4 & 0 & 0 & 0 & 0 \\
\hline 5 & 0 & 0 & 0 & 0 \\
\hline 6 & 0 & 0 & 0 & 0 \\
\hline 7 & 0 & 0 & 0 & 0 \\
\hline 8 & 0 & 0 & 0 & 0 \\
\hline 9 & 0 & 0 & 0 & 0 \\
\hline 10 & 0 & 0 & 0 & 0 \\
\hline 11 & 0 & 0 & 0 & 0 \\
\hline 12 & 0 & 0 & 0 & 0 \\
\hline 13 & 0 & 0 & 0 & 0 \\
\hline 14 & 0 & 0.24 & 0 & 0 \\
\hline 15 & 0 & 12.94 & 0 & 0 \\
\hline 16 & 0 & 15.53 & 0 & 0 \\
\hline 17 & 0 & 15.53 & 0 & 0 \\
\hline 18 & 0 & 5.76 & 0 & 0 \\
\hline 19 & 0 & 0 & 0 & 0 \\
\hline 20 & 0 & 0 & 0 & 14 \\
\hline 21 & 0 & 0 & 0 & 0 \\
\hline 22 & 0 & 0 & 0 & 0 \\
\hline 23 & 0 & 0 & 0 & 0 \\
\hline
\end{tabular}

\begin{tabular}{|r|r|r|r|}
\hline \multicolumn{5}{|c|}{ Matrix P for charger \#2 } \\
\hline $\begin{array}{r}\text { EV1 } \\
(\mathrm{kW})\end{array}$ & $\begin{array}{c}\text { EV2 } \\
(\mathrm{kW})\end{array}$ & $\begin{array}{c}\text { EV3 } \\
(\mathrm{kW})\end{array}$ & $\begin{array}{c}\text { EV4 } \\
(\mathrm{kW})\end{array}$ \\
\hline 0 & 0 & 0 & 0 \\
\hline 0 & 0 & 0 & 0 \\
\hline 0 & 0 & 0 & 0 \\
\hline 0 & 0 & 0 & 0 \\
\hline 0 & 0 & 0 & 0 \\
\hline 0 & 0 & 0 & 0 \\
\hline 0 & 0 & 0 & 0 \\
\hline 0 & 0 & 0 & 0 \\
\hline 0 & 0 & 0 & 0 \\
\hline 0 & 0 & 0 & 0 \\
\hline 15.53 & 0 & 0 & 0 \\
\hline 15.53 & 0 & 0 & 0 \\
\hline 15.53 & 0 & 0 & 0 \\
\hline 15.53 & 0 & 0 & 0 \\
\hline 15.29 & 0 & 0 & 0 \\
\hline 2.59 & 0 & 0 & 0 \\
\hline 0 & 0 & 0 & 0 \\
\hline 0 & 0 & 0 & 0 \\
\hline 0 & 0 & 9.76 & 0 \\
\hline 0 & 0 & 14.24 & 0 \\
\hline 0 & 0 & 0 & 0 \\
\hline 0 & 0 & 0 & 0 \\
\hline 0 & 0 & 0 & 0 \\
\hline 0 & 0 & 0 & 0 \\
\hline
\end{tabular}

Table 4.5 Cost Breakdown for the Analysis of Sample Data Set

\begin{tabular}{|c|c|c|c|}
\hline Energy Cost (\$) & $\begin{array}{c}\text { Demand Charge } \\
\mathbf{( \$ )}\end{array}$ & Penalty Cost (\$) & Total Cost (\$) \\
\cline { 1 - 3 } $\mathrm{KE}_{\text {Точ }}$ Energy & $\mathrm{KP} * \mathrm{P}_{\max }$ & $\mathrm{KW} * \mathrm{Time}$ & \multirow{2}{*}{284.82} \\
\hline 22.0673 & 168.8111 & 93.94 & \\
\hline
\end{tabular}


The results above minimize the total costs borne by the merchant-owned EV charging station with two chargers considering four EVs throughout the day. This method can be expanded to accommodate more EVs and chargers.

\subsection{Sensitivity Analysis}

\subsubsection{Input Data}

A sensitivity analysis has been completed by varying the penalty rates for waiting in the charging station $(K W)$. Generally, there is a fixed demand charge for the area, but the penalty for waiting can be varied based on the type of charging facility. The remaining factors of the problem are kept the same. For this study, the arrival hours of the EVs were limited to the end of the day and were randomly selected after $17 \mathrm{~h}(5: 00 \mathrm{pm})$, as shown in Table 4.6 .

Table 4.6 Arrivals of EVs to the Charging Facility

\begin{tabular}{|c|c|c|}
\hline Vehicle & Energy Requirement (kWh) & Arrival Time (hour) \\
\hline 1 & 80 & 17.9 \\
\hline 2 & 50 & 18.5 \\
\hline 3 & 24 & 19.5 \\
\hline 4 & 14 & 20.6 \\
\hline
\end{tabular}

As the penalty for waiting charge increases, while keeping the demand charges fixed, the algorithm tends to increase the demand power, to charge the EV as quickly as possible.

The following case studies consider $K W$ values equal to $0.1 \$ / \mathrm{h}, 7 \$ / \mathrm{h}, 100 \$ / \mathrm{h}, 200 \$ / \mathrm{h}$ and 300 $\$ / h$ in order to get a clear idea of the algorithm's operations. Results for the first four penalty charge cases, $K W$ equal to $0.1 \$ / \mathrm{h}, 7 \$ / \mathrm{h}$ and $100 \$ / \mathrm{h}$ and $200 \$ / \mathrm{h}$, are shown in Figure 4.3 and Figure 4.4 for Chargers \#1 and \#2 respectively. 


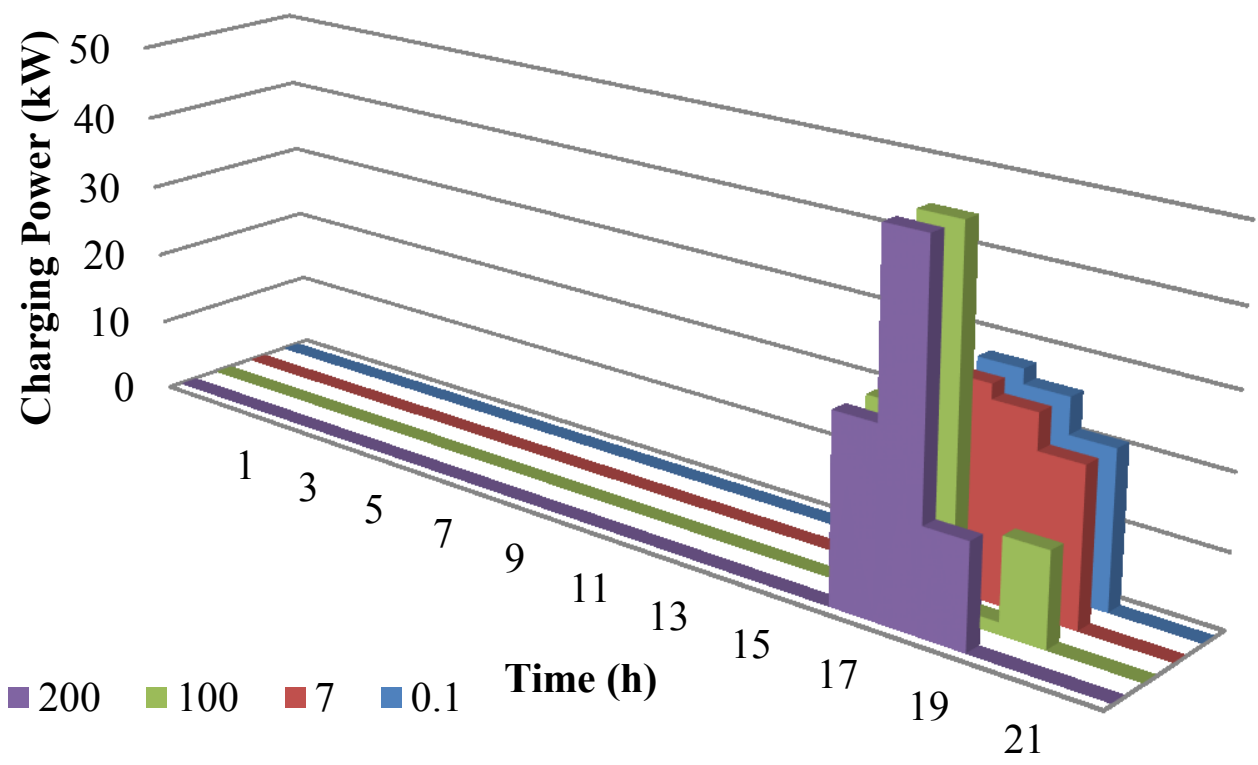

Figure 4.3 Time Line for $24 \mathrm{~h}$ for Charger \#1, KW=0.1, 7, 100 and $200 \$ / \mathrm{h}$.

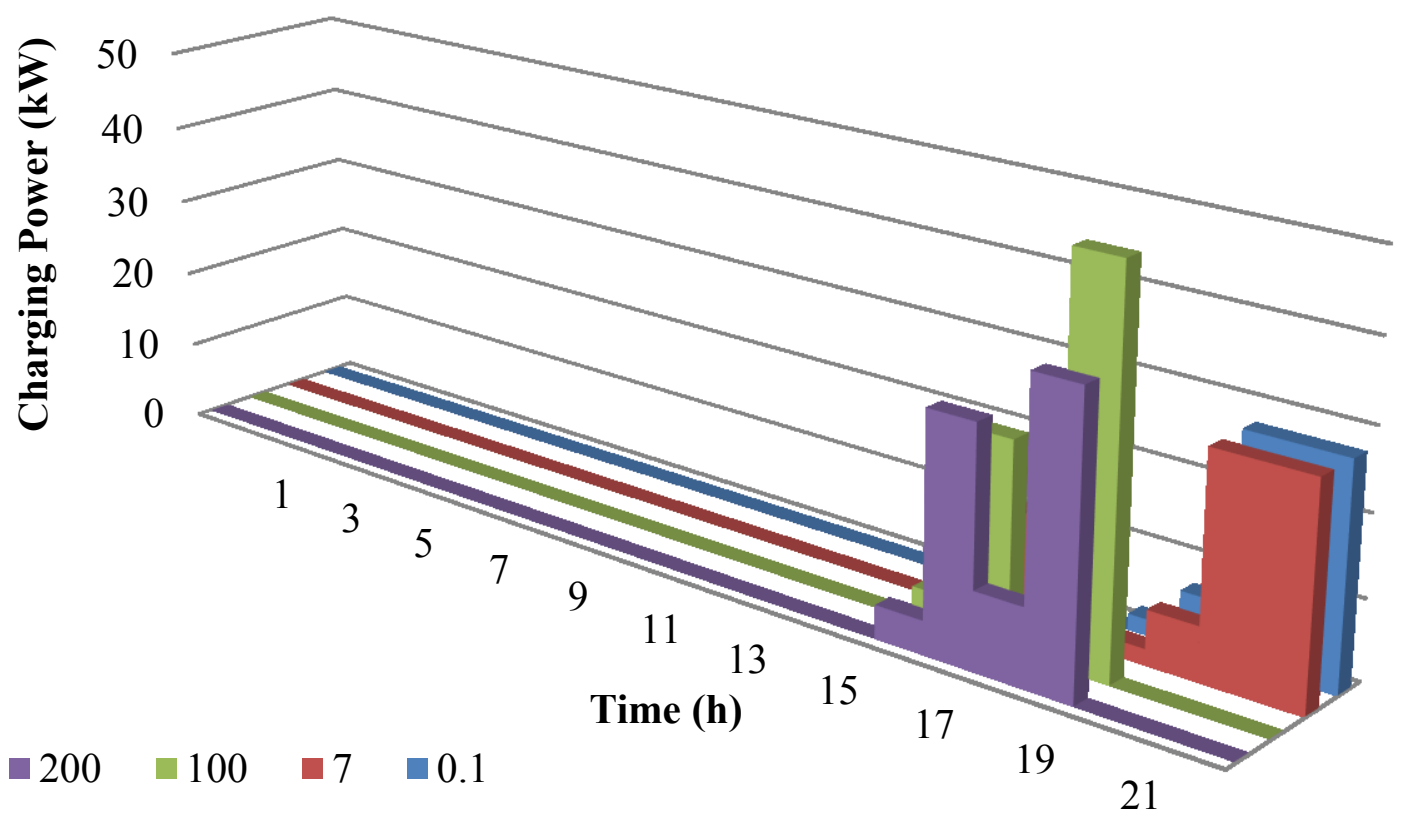

Figure 4.4 Time Line for $24 \mathrm{~h}$ for Charger \#2, KW=0.1, 7, 100 and $200 \$ / \mathrm{h}$

In the following subsections, different types of analyses are carried out for the results obtained in this section. 


\subsubsection{Effect on the Total Charging Cost}

A breakdown of the cost values is given in Table 4.7.

Table 4.7 Cost Breakdown of Each Case

\begin{tabular}{|r|r|r|r|r|}
\hline KW (\$/h) & Energy Cost (S) & Demand Charge (\$) & Penalty Cost (\$) & Total Cost (\$) \\
\hline 0.1 & 14.01 & 300.19 & 1.09 & 315.29 \\
\hline 7 & 14.01 & 300.19 & 76.41 & 390.61 \\
\hline 100 & 14.90 & 551.41 & 525.00 & 1091.31 \\
\hline 200 & 15.04 & 638.47 & 950.00 & 1603.51 \\
\hline 300 & 15.08 & 663.07 & 1400.00 & 2078.15 \\
\hline
\end{tabular}

Since all the EVs arrived within a short period of time, the effect from the TOU tariff on varying the energy cost is insignificant. Therefore, change of the rate of penalty costs for waiting affected only demand cost and total penalty cost. These two cost values and their sum are plotted against the rate of penalty cost in Figure 4.5. The associated effect on the total waiting time is presented in Table 4.8. 


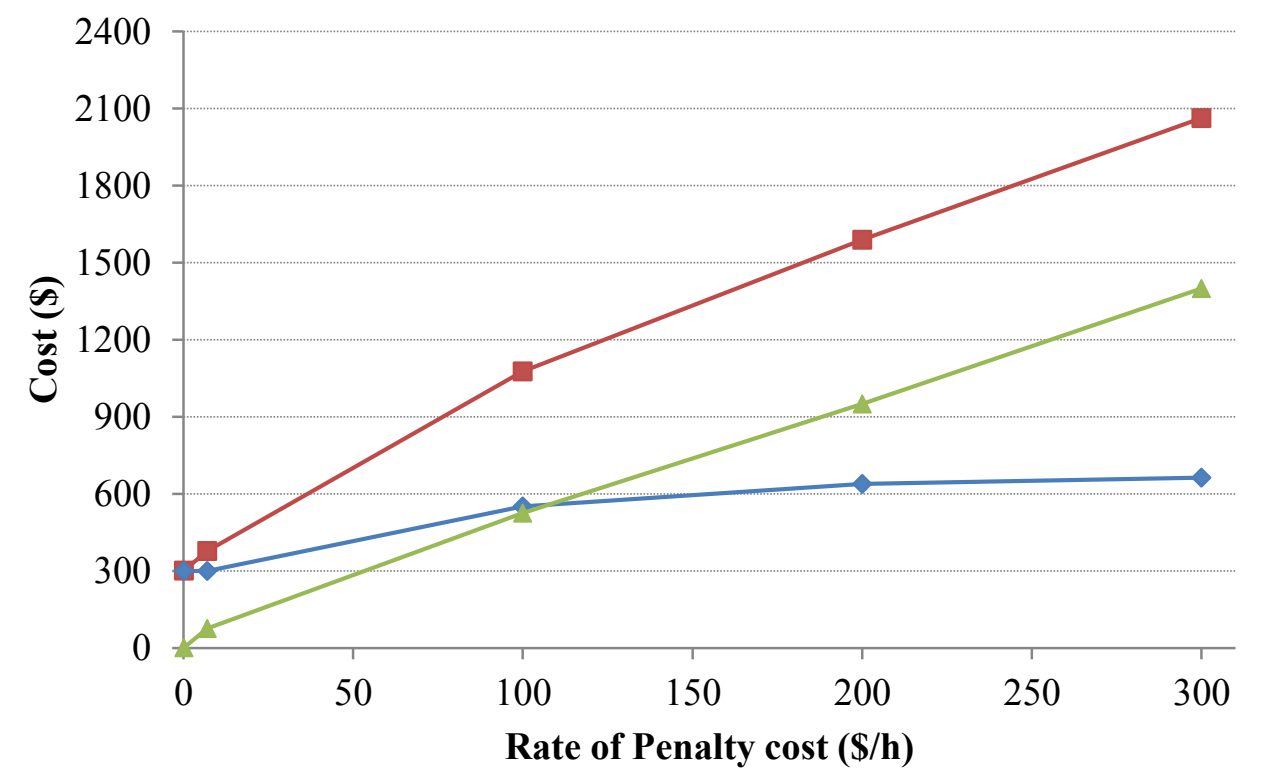

$\rightarrow$ Demand charge + Penalty cost $\multimap$ Demand charge $\longrightarrow$ Total Penalty cost

Figure 4.5 Cost Variation against Rate of Penalty Cost

Table 4.8 Total Waiting Time for Each Value of the Penalty for Waiting $(K W)$

\begin{tabular}{|c|c|}
\hline $\boldsymbol{K} \boldsymbol{W} \mathbf{( \$ / h )}$ & Waiting Time (h) \\
\hline 0.1 & 10.9 \\
\hline 7 & 10.92 \\
\hline 100 & 5.25 \\
\hline 200 & 4.75 \\
\hline 300 & 4.67 \\
\hline
\end{tabular}

In Figure 4.5 it can be observed that cost summation of demand cost and total penalty cost is increasing at a decreasing rate, due to the ability to employ parallel charging. One shall also notice that, since energy cost is almost constant, the total cost variation has the shape similar to summation of demand cost and total penalty cost.

The relationship between the demand charge and the total waiting time for different KW values is shown in Figure 4.6. 


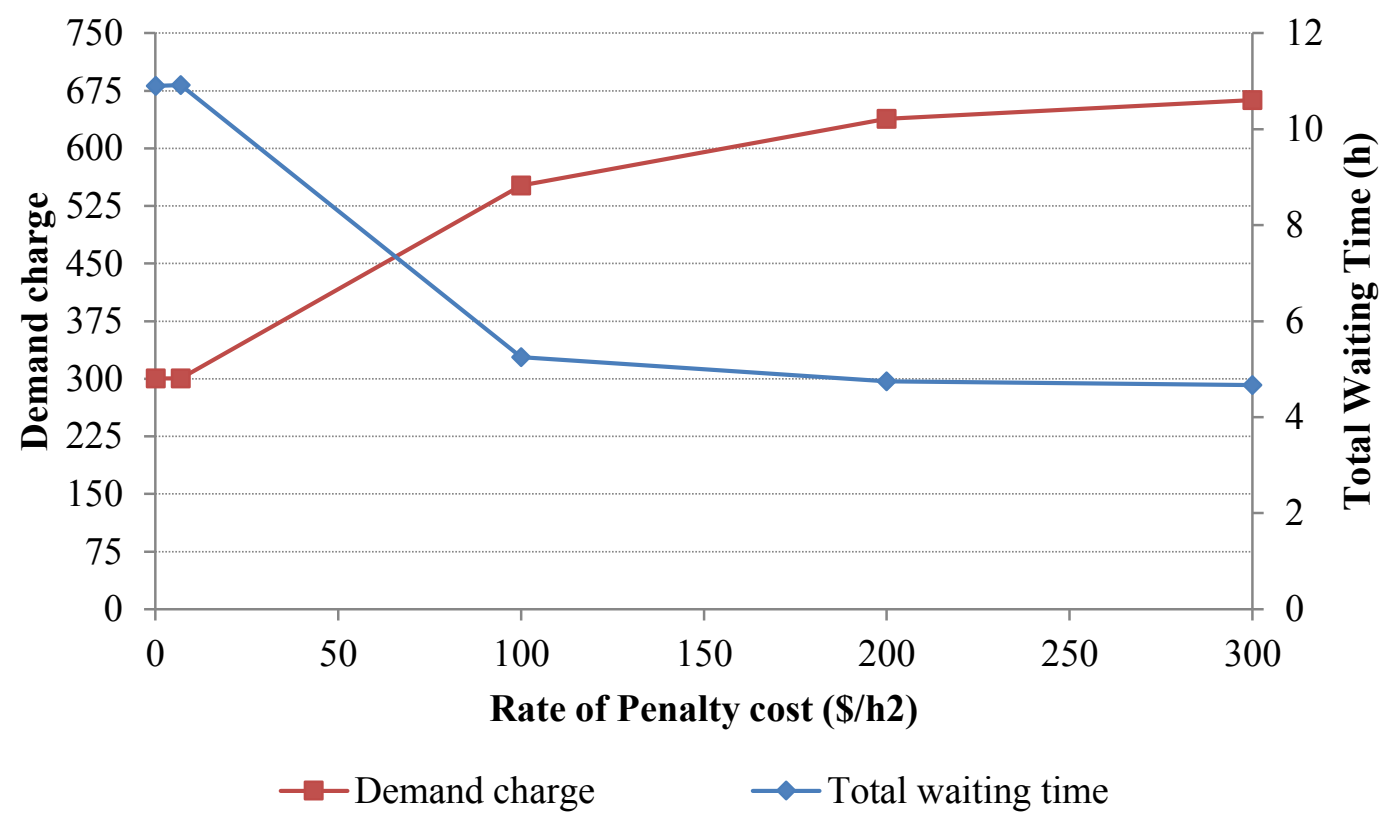

Figure 4.6 Demand Charge Variation for Different Penalty Rates

As the penalty rate $K W$ increases, the algorithm reduces waiting time to charge EVs at a higher power. Since there are multiple chargers available, at higher $K W$ values, EVs are charged in parallel to reduce the total cost.

\subsubsection{Effect on the Total Cost Variation Throughout the Day}

Variation of the total cost of the charging facility along the time line is shown in this study. Since demand charge solely depends on the recorded maximum power, it is not varying with the time and, as such, was not considered in Figure 4.7.

\subsubsection{Results from the sensitivity analysis}

For the same energy requirements, when the penalty for waiting is increasing, the highest cost will be faced at the same hour, which is the $19^{\text {th }}$ hour. Increasing the penalty for waiting causes a reduction in the waiting time and, consequently, an increase in the total penalty cost when there is a waiting time period. This can be seen in Figure 4.7 by the sharp increase in the total charging cost around the $19^{\text {th }}$ hour. 


\subsubsection{Results from the sensitivity analysis vs. analysis on sample data set}

The energy requirement is equal for the sample data set and all other cases. The analysis on the sample data set has used the penalty rate of $7 \$ / \mathrm{h}$ and total cost is spread throughout the day, while all the other analyses have higher cost around the $19^{\text {th }}$ hour.

The main reason for this is the variation of arrival times. Arrivals of EVs for the sample are spread throughout the day and therefore each EV has less time to be in the queue. In all other cases, EVs are arriving during a short period of time, where some EVs must wait in the queue to be charged. To reduce the penalty for waiting, higher power was used to charge the EVs, causing higher cost for all the other cases.

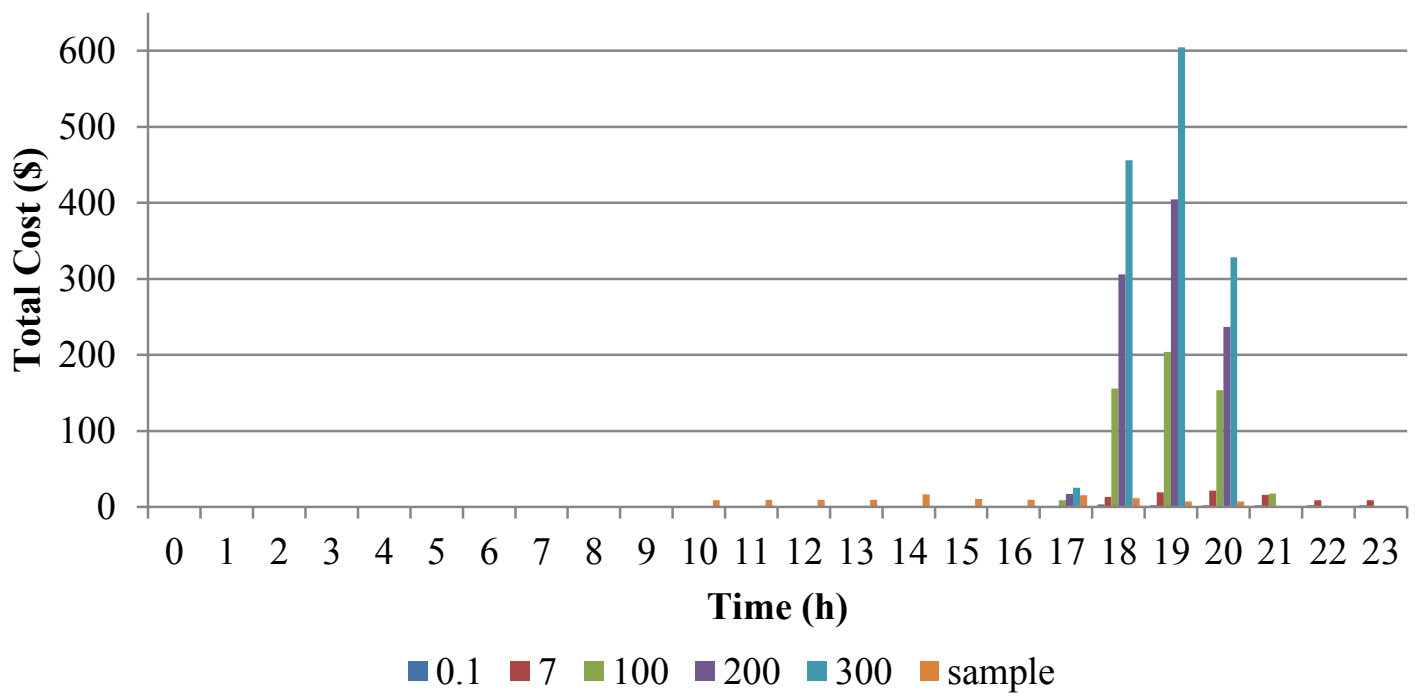

Figure 4.7 Total Cost for the Charging Facility for Different Penalty Cost Rates

\subsubsection{Effect on the Total Charging Cost per EV}

The effect of KW variation on the total charging cost per EV is shown in Figure 4.8. Demand charge was distributed among the EVs, based on the ratio of maximum charging power of each EV. 


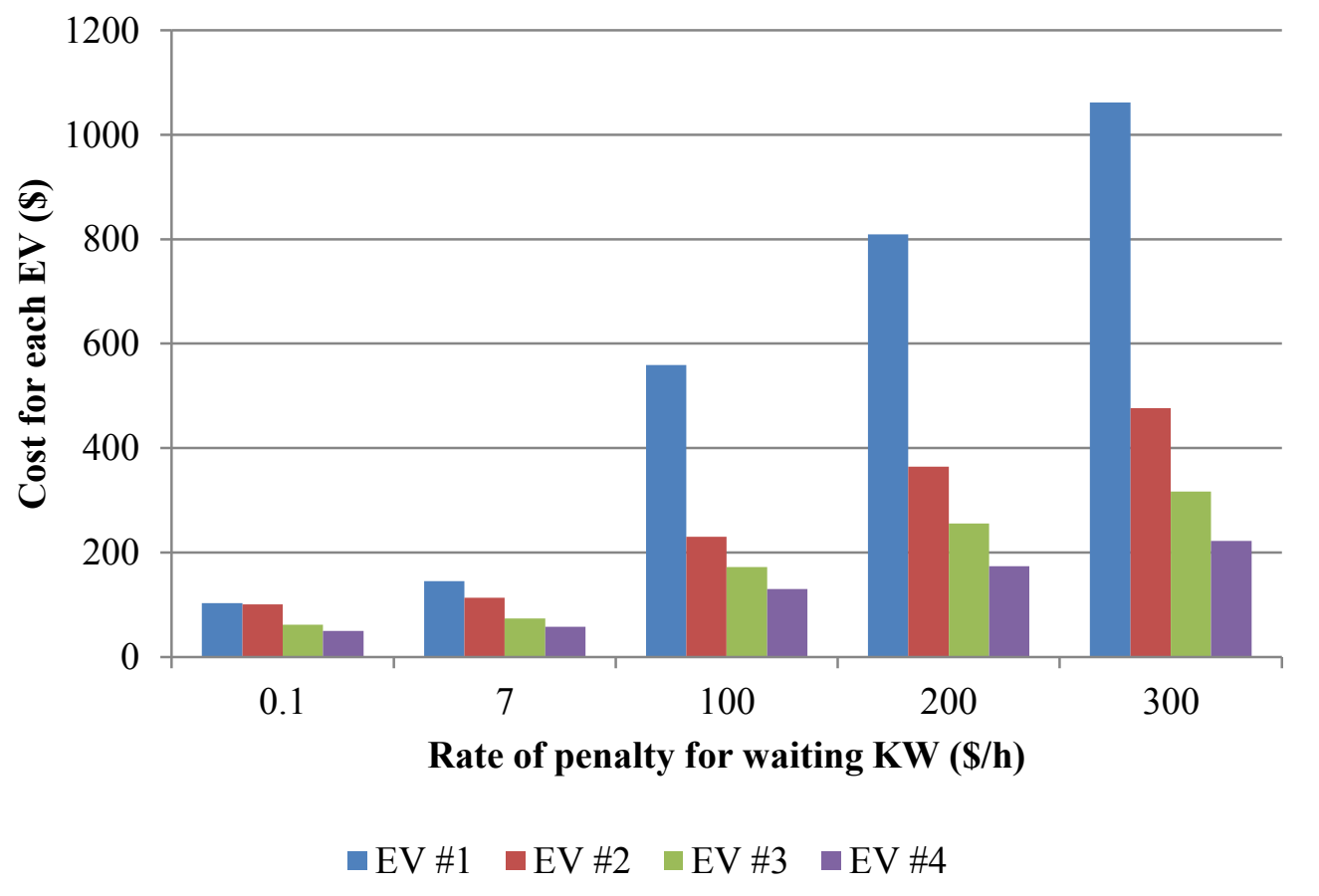

Figure 4.8 Cost for Each EV for Different Rates of Penalty Costs

\subsubsection{Results from the sensitivity analysis}

The resulting energy requirement of each $\mathrm{EV}$ is: $1^{\text {st }} \mathrm{EV}>2^{\text {nd }} \mathrm{EV}>3^{\text {rd }} \mathrm{EV}>4^{\text {th }} \mathrm{EV}$.

It can be seen that increasing the penalty for waiting will result in a significant impact on the cost of individual EVs, based on their energy requirements. When the penalty rate is increasing, the individual cost of each EV is increasing drastically. This is caused by two main factors:

- When the energy requirement is high, the charging time becomes longer, causing an increase in the penalty for waiting.

- As the algorithm minimizes the cost by reducing time and increasing charging power in an optimum manner, it contributes to an increase in the demand charge. 


\subsubsection{Results from the sensitivity analysis vs. analysis on sample data set}

The difference between the analysis on the sample data set and the case of $K W=7 \$ / \mathrm{h}$, is the arrival time of each EV. It can be observed that arriving in a busy period can cause a higher cost.

\subsubsection{Comparison with Related Work in the Literature}

There are no existing methods that address this problem of EV charging scheduling from a merchant-owned charging station's perspective. In spite of that, the following two works must be highlighted.

With the approach shown in [36], it is possible to obtain the optimum charging schedule for a fleet of EVs to minimize their charging cost. In our approach, however, we address the issue from the charging facility owner's point of view, so that owner will be able to develop a good economic model for their charging facility.

Research paper [31] mainly focuses on developing an optimum charging schedule, considering all the grid capacity constraints, to minimize the impact on the grid. In our approach, however, grid constraints are not considered, except for power capacity of the transformer. It was assumed that for the optimum charging schedule, negative impact on the grid is insignificant. From the charging facility point of view, the owner's objective is to minimize the cost.

\subsection{Summary}

Electric vehicle charging at a charging facility forms a hybrid system consisting of a continuous and a discrete function. This hybrid system was approximated and converted into a mixedinteger linear problem and it was solved using the MOSEK optimization toolbox in MATLAB. Due to the complexity of the problem, loss of energy at the charging facility was assumed to be zero.

The problem was solved using three sets of 3D matrices. These are: 
- Status of the charging of electric vehicle.

- Status when electric vehicle starts charging.

- Charging power of each vehicle at each charger at each time slot.

The objective function consists of energy cost, maximum demand charge and penalty for waiting. It was optimized under: the constraints of 3D matrices (there should be only one car at one charger, each EV should be charged only during one continuous period of time, recorded maximum value of the summation of power is set as the maximum power consumption at the charging facility); power limitation of the chargers and the transformer connected to the charging facility; and ensuring the charging requirements of each EV are met.

The optimum solution is given as a row matrix consisting of answers to all the variables including each cell in each 3D matrix. Charging time, waiting time, charging power and which charger was used for each electric vehicle can be extracted from the row matrix.

An analysis for a sample data set and a sensitivity analysis have been carried out for four sets of vehicles arriving in four different times during the day to analyze the system and results were discussed through tables and charts. Like the analysis done for the charging facility with a single charger, penalty for waiting time has been chosen as the variable for the sensitivity analysis, as it is the only factor that the charging facility owner can control. Results were obtained and discussed in this chapter. 


\section{Chapter 5}

\section{Conclusion}

With increasing adoption of EVs, deployment of public EV charging facilities will also be a necessity. To minimize the cost of charging for merchant-owned charging facilities, it is imperative to have algorithms to compute the optimum EV charging schedule.

There can be charging stations with a single charger or multiple chargers. Two separate methodologies to minimize the cost of EV charging at a merchant-owned charging facility are presented this thesis. Cost minimization was completed from the charging facility owner's perspective.

\subsection{Chapter Wise Conclusion}

\subsubsection{Chapter 1: General Introduction}

The importance of electric vehicles to the transport sector and the increasing demand for the charging requirements of electric vehicles were explained with facts and figures. The motivation and objectives of this thesis were presented and discussed.

\subsubsection{Chapter 2: Literature Survey}

Several research studies have been undertaken on the topic of optimizing the schedule of electric vehicle charging to achieve various objectives. No research has proposed a methodology to optimize the cost of EV charging from the charging facility owner' perspective. A few research studies for optimal control of hybrid systems were discussed.

The performance of EV charging with a single charger is a hybrid discrete-continuous optimization problem, similar to the steel annealing process [45]. So the optimization methodology used in [45] was used to optimize the cost of EV charging at a merchant-owned EV 
charging facility with a single charger. Results from sample data set and a sensitivity analysis demonstrate the efficacy of the proposed method.

\subsubsection{Chapter 3: Electrical Vehicle Charging for a Charging Facility with a Single Charger}

There are many research papers which have proposed a methodology to determine an optimum charging schedule in an EV charging station. Those optimizations are undertaken from the customer's point of view or based on the impact on the grid [22] - [40]. However, the proposed approach was developed to determine the charging schedule from a merchant-owned charging station owner's perspective. This is a nonconvex non-differentiable optimization problem. In this algorithm, however, the problem is transformed into multiple smaller and simpler convex problems that can be easily solved by classical techniques.

\subsubsection{Chapter 4: Electrical Vehicle Charging for a Charging Facility with Multiple Chargers}

The optimum schedule for charging electric vehicles at a merchant-owned charging facility with multiple chargers can be obtained by solving a mixed-integer linear formulation proposed and developed in this chapter. It is solved using the MOSEK optimization toolbox in MATLAB. The problem was solved using 3-dimentional matrices. The final solution is given as a row matrix, which provides which electric vehicle will be charged at which charger, during which time period for the optimum schedule. Apart from that, waiting time, power consumption, and energy costs can also be identified from the solution matrix.

Many research studies were carried out to obtain an optimal EV charging schedule to achieve different objectives. The problem was mainly formulated from the customer point of view or based on the impact on the grid. But none of the research studies have been undertaken to optimize the cost of EV charging from the charging facility owner's point of view. The 
methodology presented in this chapter can be applied to a merchant-owned charging facility with multiple chargers and can also inform the charging prices to the customer a day ahead.

\subsection{Research Contribution}

A day-ahead EV charging schedule can be obtained using the proposed methodologies in Chapters 3 and 4. Customers then have the ability to select the best option based on the list of charging facilities around the area. The consumer choice involves tradeoffs between charging cost and speed of charging.

In this thesis, the tariff structure and demand charge rates are fixed and the charging facility has no control over the number of EVs coming to the charging facility and their charging requirements. However, penalty cost for an EV waiting in a queue before charging can be modified by the merchant in order to control the total charging cost. Charging facilities located in suburban areas can have higher penalty rates, while charging facilities within or near the city core such as commercial buildings and offices can have lower penalty rates. Case studies presented in this thesis have shown that the higher the penalty for waiting time, the higher the total charging cost for the facility owner. But with more chargers available at the facility, total cost will increase at a lower rate. 


\subsection{Future Work}

\section{- Charging facility with a single charger}

For future work, this model can be further improved by introducing a varying efficiency level with the charging power, and replacing a flat rate of tariff with a Time of Use tariff to calculate the energy cost.

\section{- Charging facility with multiple chargers}

Loss of energy can be added to the formulation to improve the cost calculation. Loss of energy of an individual EV can be calculated by using an average charging power of the EV. Since it is nonlinear in nature, it was not included in this optimization problem with multiple chargers.

In both cases, demand charge is calculated for a month. In these algorithms, it was considered for a day. In industry applications, the maximum recorded demand during the month can be divided into individual days to calculate the cost or a business model can be developed to calculate the daily allocation of the monthly demand charge. 


\section{References}

[1] International Energy Agency, “Global EV outlook 2016,” France, May 2016.

[2] Pollutant Inventories and Reporting Division of Environment Canada, "Environment and Climate Change Canada (2017) National Inventory Report 1990-2015.”

[3] “International Energy Outlook 2016,” U.S. Energy Information Administration, May 2016.

[4] Clean Energy Ministerial, "Government Fleet Declaration-Electric Vehicles Initiative," Morocco, 16-Nov-2016.

[5] "Electric vehicle charging incentive program." [Online]. Available:

http://www.mto.gov.on.ca/english/vehicles/electric/charging-incentive-program.shtml.

[Accessed: 07-May-2017].

[6] "Fact sheet: Plug-in electric vehicle deployment," Environmental and Energy Study Institute, Washington, DC, Oct. 2012.

[7] N. Lutsey, S. Searle, S. Chambliss, and A. Bandivadekar, "Assessment of leading electric vehicle promotion activities in United States cities," The International Council on Clean Transportation, Washington DC, Jul. 2015.

[8] "Ultra-Fast-Charging for electric vehicles starting in Europe.” Ultra E, Ultra charging study Europe, 18-Oct-2016.

[9] Working Group 3 - Charging Infrastructure and Power Grid Integration, "Charging Infrastructure for Electric Vehicles in Germany," German National Platform for Electric Mobility, 2016.

[10] "Electric Vehicles Chargers Ontario.” [Online]. Available: http://www.mto.gov.on.ca/english/vehicles/electric/electric-vehicle-chargers-ontario.shtml. [Accessed: 07-May-2017]. 
[11] SAE Hybrid Committee, "SAE Charging configuration and Ratings Terminology." SAE international, 2011.

[12] “Supercharger | Tesla Canada." [Online]. Available:

https://www.tesla.com/en_CA/supercharger. [Accessed: 15-May-2017].

[13] "Tesla Charging | Tesla Canada.” [Online]. Available:

https://www.tesla.com/en_CA/models-charging\#/onthego. [Accessed: 07-May-2017].

[14] ChAdeMO, “CHAdeMO ANNOUNCES HIGH POWER (150KW) VERSION OF THE PROTOCOL."

[15] "Members - Chademo Association." [Online]. Available:

https://www.chademo.com/membership/members/. [Accessed: 18-May-2017].

[16] “Tesla - CHAdeMO Adapter." [Online]. Available:

https://shop.teslamotors.com/collections/model-s-charging-adapters/products/chademoadapter. [Accessed: 16-May-2017].

[17] "What is the CCS?: Charging Interface Initiative e. V. (CharIN e. V.)." [Online]. Available: http://www.charinev.org/ccs-at-a-glance/what-is-the-ccs/. [Accessed: 15-May2017].

[18] Volkswagen, “2016 e-Golf,” brochures, 2016.

[19] “BMW i3 | PluginCars.com.” [Online]. Available: http://www.plugincars.com/bmwi3.html. [Accessed: 18-May-2017].

[20] IHS Automotive, "Global EV Charging Stations to Skyrocket by 2020, IHS Report Says | IHS Online Newsroom.” [Online]. Available: http://news.ihsmarkit.com/pressrelease/automotive/global-ev-charging-stations-skyrocket-2020-ihs-report-says. [Accessed: 18-May-2017]. 
[21] A. N. Michel, L. Hou, and D. Liu, Stability of dynamical systems: continuous, discontinuous, and discrete systems. Boston: Birkhauser, 2008.

[22] H. Liu, Y. Yang, J. Qi, J. Li, H. Wei, and P. Li, "Frequency droop control with scheduled charging of electric vehicles," IET Gener. Transm. Distrib., vol. 11, no. 3, pp. 649-656, 2017.

[23] H. Liu, J. Qi, J. Wang, P. Li, C. Li, and H. Wei, "EV Dispatch Control for Supplementary Frequency Regulation Considering the Expectation of EV Owners," IEEE Trans. Smart Grid, vol. PP, no. 99, pp. 1-1, 2016.

[24] H. N. T. Nguyen, C. Zhang, and M. A. Mahmud, "Optimal Coordination of G2V and V2G to Support Power Grids With High Penetration of Renewable Energy," IEEE Trans. Transp. Electrification, vol. 1, no. 2, pp. 188-195, Aug. 2015.

[25] L. Cheng, Y. Chang, and R. Huang, "Mitigating Voltage Problem in Distribution System With Distributed Solar Generation Using Electric Vehicles," IEEE Trans. Sustain. Energy, vol. 6, no. 4, pp. 1475-1484, Oct. 2015.

[26] K. Strunz, E. Abbasi, and D. N. Huu, "DC Microgrid for Wind and Solar Power Integration," IEEE J. Emerg. Sel. Top. Power Electron., vol. 2, no. 1, pp. 115-126, Mar. 2014.

[27] M. Ghofrani, A. Arabali, M. Etezadi-Amoli, and M. S. Fadali, "Smart Scheduling and Cost-Benefit Analysis of Grid-Enabled Electric Vehicles for Wind Power Integration," IEEE Trans. Smart Grid, vol. 5, no. 5, pp. 2306-2313, Sep. 2014.

[28] E. Sortomme and M. A. El-Sharkawi, "Optimal Scheduling of Vehicle-to-Grid Energy and Ancillary Services," IEEE Trans. Smart Grid, vol. 3, no. 1, pp. 351-359, Mar. 2012. 
[29] M. H. K. Tushar, C. Assi, M. Maier, and M. F. Uddin, "Smart Microgrids: Optimal Joint Scheduling for Electric Vehicles and Home Appliances," IEEE Trans. Smart Grid, vol. 5, no. 1, pp. 239-250, Jan. 2014.

[30] Y. He, B. Venkatesh, and L. Guan, “Optimal Scheduling for Charging and Discharging of Electric Vehicles," IEEE Trans. Smart Grid, vol. 3, no. 3, pp. 1095-1105, Sep. 2012.

[31] B. Sun, Z. Huang, X. Tan, and D. H. K. Tsang, "Optimal Scheduling for Electric Vehicle Charging with Discrete Charging Levels in Distribution Grid," IEEE Trans. Smart Grid, vol. PP, no. 99, pp. 1-1, 2016.

[32] Y. Song, Y. Zheng, and D. J. Hill, “Optimal Scheduling for EV Charging Stations in Distribution Networks: A Convexified Model," IEEE Trans. Power Syst., vol. 32, no. 2, pp. 1574-1575, Mar. 2017.

[33] O. Beaude, S. Lasaulce, M. Hennebel, and I. Mohand-Kaci, "Reducing the Impact of EV Charging Operations on the Distribution Network," IEEE Trans. Smart Grid, vol. 7, no. 6, pp. 2666-2679, Nov. 2016.

[34] L. Gan, U. Topcu, and S. H. Low, “Optimal decentralized protocol for electric vehicle charging," IEEE Trans. Power Syst., vol. 28, no. 2, pp. 940-951, May 2013.

[35] G. Lacey, G. Putrus, and E. Bentley, "Smart EV charging schedules: supporting the grid and protecting battery life," IET Electr. Syst. Transp., vol. 7, no. 1, pp. 84-91, 2017.

[36] J. Hu, S. You, J. Oestergaard, M. Lind, and Q. Wu, "Optimal Charging Schedule of an Electric Vehicle Fleet," in Universities' Power Engineering Conference (UPEC), Proceedings of 2011 46th International, 2011, pp. 1-6. 
[37] A. Gusrialdi, Z. Qu, and M. A. Simaan, "Distributed Scheduling and Cooperative Control for Charging of Electric Vehicles at Highway Service Stations," IEEE Trans. Intell. Transp. Syst., vol. PP, no. 99, pp. 1-15, 2017.

[38] C. Jin, J. Tang, and P. Ghosh, "Optimizing Electric Vehicle Charging: A Customer's Perspective," IEEE Trans. Veh. Technol., vol. 62, no. 7, pp. 2919-2927, Sep. 2013.

[39] V. del Razo and H. A. Jacobsen, "Smart Charging Schedules for Highway Travel With Electric Vehicles," IEEE Trans. Transp. Electrification, vol. 2, no. 2, pp. 160-173, Jun. 2016.

[40] Y. M. Wi, J. U. Lee, and S. K. Joo, "Electric vehicle charging method for smart homes/buildings with a photovoltaic system," IEEE Trans. Consum. Electron., vol. 59, no. 2, pp. 323-328, May 2013.

[41] M. Tabari and A. Yazdani, “An Energy Management Strategy for a DC Distribution System for Power System Integration of Plug-In Electric Vehicles," IEEE Trans. Smart Grid, vol. 7, no. 2, pp. 659-668, Mar. 2016.

[42] K. N. Kumar, B. Sivaneasan, P. H. Cheah, P. L. So, and D. Z. W. Wang, "V2G Capacity Estimation Using Dynamic EV Scheduling," IEEE Trans. Smart Grid, vol. 5, no. 2, pp. 1051-1060, Mar. 2014.

[43] Q. Zhai, X. Guan, and F. Gao, “Optimization Based Production Planning With Hybrid Dynamics and Constraints," IEEE Trans. Autom. Control, vol. 55, no. 12, pp. 2778-2792, Dec. 2010.

[44] M. Schori, T. J. Boehme, B. Frank, and B. P. Lampe, "Optimal Calibration of Map-Based Energy Management for Plug-In Parallel Hybrid Configurations: A Hybrid Optimal Control Approach," IEEE Trans. Veh. Technol., vol. 64, no. 9, pp. 3897-3907, Sep. 2015. 
[45] Y. C. Cho, W. H. Kwon, and C. G. Cassandras, “Optimal control for steel annealing processes as hybrid systems," in Proceedings of the 39th IEEE Conference on Decision and Control (Cat. No.00CH37187), 2000, vol. 1, pp. 540-545 vol.1.

[46] "Business Electricity Rates | Toronto Hydro Corporation.” [Online]. Available: http://www.torontohydro.com/sites/electricsystem/business/rates/Pages/busrates.aspx. [Accessed: 05-May-2017].

[47] A. Genovese, F. Ortenzi, and C. Villante, "On the energy efficiency of quick DC vehicle battery charging," in EVS28 Int. Electr. Veh. Symp. Exhib, 2015, pp. 1-7.

[48] “Model S Specifications | Tesla Canada." [Online]. Available:

https://www.tesla.com/en_CA/support/model-s-specifications. [Accessed: 15-May-2017].

[49] "Model X Specifications | Tesla Canada.” [Online]. Available:

https://www.tesla.com/en_CA/support/model-X-specifications. [Accessed: 15-May-2017].

[50] “2017 Nissan LEAF® SV | Price \& Specs.” [Online]. Available:

https://www.nissanusa.com/electric-cars/leaf/versions-specs/version.sv.html. [Accessed: 15May-2017].

[51] “iOn - Peugeot UK.” [Online]. Available: http://www.peugeotpress.co.uk/model-36pack-373.htm. [Accessed: 15-May-2017].

[52] "Medium distribution transformers (316-2,499 kVA) - Distribution Transformers (Transformers) | ABB.” [Online]. Available: http://new.abb.com/products/transformers/distribution/medium. [Accessed: 15-May-2017]. [53] ABB, "Green distribution transformer program Partnership for a sustainable environment," Oct. 2015. 